\title{
Assessing the effect of urban form on social sustainability: a proposed 'Integrated Measuring Tools Method' for urban neighborhoods in Dubai
}

\author{
S. M. Hossein Alipour ${ }^{1}$ and Khaled Galal Ahmed ${ }^{2 *}$
}

\begin{abstract}
Among the three pillars of sustainability, social sustainability has received the least attention, especially among the studies addressing the sustainable housing development in Dubai's urban neighborhoods. Unfortunately, these neighborhoods are not showing enough vibrancy of their public spaces and amenities which seemingly undermined their social sustainability. The lack of a comprehensive tool that can assess the interlinked indicators of social sustainability in urban neighborhoods has urged the research to propose an Integrated Measuring Tools Method (IMTM), that incorporates relevant computational simulation techniques alongside the appropriate conventional qualitative tools. The proposed IMTM was utilized in assessing the social sustainability indicators within the urban form of an existing neighborhood in Dubai. The assessment revealed that various urban form characteristics including; density, land-use, mobility options, mobility networks, streets layouts, and the built environment's safety and aesthetic qualities, are the main factors undermining social sustainability in the studied locality. The results informed a set of suggested redevelopment strategies/guidelines for this neighborhood that takes into consideration the exiting constraints and opportunities. These included; increasing density by infill development, redefining land-use to achieve diversity in housing types and decentralized amenities, diversifying mobility options, improving the spatial integration of the mobility networks while restraining the private cars movement, improving accessibility, enriching urban landscape, and finally enhancing the quality of amenities and services. A social sustainability redevelopment scenario was suggested based on these strategies. When compared to the exiting neighborhood utilizing the IMTM, it proved significantly better attainment of social sustainability principles. So, it might be claimed that the proposed IMTM and its outcomes proved to be a valid basis for assessing, redeveloping and validating social sustainability of existing neighborhoods with similar typology in Dubai, and potentially in the region.
\end{abstract}

Keywords: Social sustainability, Urban redevelopment, Urban form, Housing, Neighborhood, Dubai

\section{Introduction}

In line with the growing attention to sustainability in the present era, the number of cities pursuing adoption of sustainable design and planning approaches is

\footnotetext{
${ }^{*}$ Correspondence: kgahmed@uaeu.ac.ae

${ }^{2}$ Emirates Center for Happiness \& Wellbeing, United Arab Emirates

University, P. O. Box: 13393, Al Ain 15551, UAE

Full list of author information is available at the end of the article
}

continuously increasing (Kolczak 2017; Hassan and Lee 2015). But unfortunately, social sustainability has not received as much attention as the other two pillars of sustainability, namely, environmental and economic dimensions. As urban neighborhoods are the foremost environment where people are socially exposed to, so, the quality of their experience is highly dependent on the urban attributes of these neighborhoods. Social sustainability, in specific, is highly contextual and do vary 
depending on the urban context-related specificities and differences (Jenks and Jones 2010).

The urban form of a neighborhood with its physical and spatial attributes makes it unique in its kind and brings a variety of social opportunities and experiences to its residents (Avila and Ines 2001). Such attributes influence residents' life in one way or another, depending on a variety of factors such as social stratum, age, and gender (Carmona et al. 2003). Therefore, the relationship between 'people' and their 'built environment' is typically a reciprocal process in which each one of them has some effects on the other (Carmona et al. 2003; Lynch 1981; Jalaladdini and Oktay 2012). This makes the context-specific considerations of the community's interests and needs in the design of urban neighborhoods a fundamental contributor to the residents' tendency to rely on the locality in satisfying their local needs (Holland et al. 2007). Such reliance would improve the neighborhood's vibrancy and help create social interactions and a lively social environment (Newman 1996).

Within the Gulf Countries Council (GCC) region, a limited number of studies has been conducted for assessing and attaining social sustainability especially on the neighborhood redevelopment level. Dubai, a rapidly growing city and a leading economy in the GCC region, is not an exception. In Dubai, the accelerating pace of urban development has overlooked achieving social sustainability in housing developments to some extent. This is particularly noticed in the local government subsidized Emirati single-family housing neighborhoods, which represent the most dispersed pattern of housing development in the city and occupying about $14 \%$ of its urbanized land (Alawadi 2017).

\section{Research questions, objectives and method}

In Dubai, a widely noticed issue in most Emirati neighborhoods, is the questionable quality of urban spaces and the lack of vibrancy in the public realm. While the centers of most of these neighborhoods were originally planned to include the locally needed public services and amenities and, thus, supposedly made to attract people and bring about the opportunity for social interactions, most of these centers have been left fully or partially abandoned. So, based on these initial observations, the main triggered questions were: how socially sustainable are these neighborhoods? and because there are no obvious strategies for assessing and redeveloping social sustainability in exiting urban neighborhoods in Dubai, how can they be redeveloped to be more socially sustainable?

The link between physical and social characteristics of neighborhoods is complex and influenced by the reciprocal relationship between people and the urban form (Carmona et al. 2003). Hence, for improving social sustainability in neighborhoods, it is necessary first to determine a valid and reliable understanding of the social sustainability principles and its related indicators. This is the first research objective, where relevant literature review was consulted. The second objective is to devise a new comprehensive multi-tools methodological approach that for assessing social sustainability indicators in the existing Emirati neighborhoods in Dubai. This originated from the fact that there is a clearly obvious gap in the utilized assessment tools for social sustainability aspects specifically those pertaining to urban form spatial characteristics in the current applied methods in social sustainability assessment research. Most of the conventional methods for assessing social sustainability were intensively dependent on quantitative and statistic-based administered questionnaires which are occasionally coupled with some qualitative tools such as filed observations (Ghahramanpouri et al. 2013).

In response to the need for such a comprehensive and reliable methodical approach that could help tackle this issue, and as detailed below, the research proposed an Integrated Measuring Tools Method (IMTM) that is basically initiated through combining quantitative computational techniques with conventional qualitative tools to bridge this gap. The third objective is to use this devised method for assessing social sustainability in an existing Emirati single-family housing 'model' neighborhood in Dubai. Accordingly, relevant generalizable redevelopment strategies could be defined. The fourth objective is to validate the proposed method through implementing the defined redevelopment strategies resulting from its assessment process in a redevelopment scenario for the studied case study. Then, assess the social sustainability in the redeveloped urban form utilizing the same Integrated Measuring Tools Method (IMTM).

As explained later, $\mathrm{Al}$ Barsha North 2 was selected as a case study representing a repetitive model for the recently developed Emirati single-family housing neighborhoods in Dubai. The research then embarked on undertaking two consecutive analytical phases. First, is the assessment of the social sustainability indicators for Al Barsha North 2. Such an assessment identified the weaknesses and opportunities for redevelopment which help devise appropriate strategies and measures for redevelopment. The defined redevelopment strategies guided a schematic redesign for the neighborhood. Second, is the assessment of the redevelopment schematic design and comparing its social sustainability qualities with those of the current neighborhood before the redevelopment. This actually validated the proposed IMTM's effectiveness, and the extent to which it contributed to the enhancement of social sustainability in the studied neighborhood. 


\section{A conceptual framework for social sustainability principles and indicators}

Defining the principles and indicators of social sustainability in urban neighborhoods is by no means a straightforward process given the qualitative and sometime subjective nature of the topic and the absence of a unified vision about it. Nonetheless, based on a conducted literature review, ten principles of social sustainability in urban neighborhoods were found widely accepted among several researchers and scholars. As briefly presented below, these principles and their related indicators were utilized in establishing a conceptual framework that was utilized in assessing social sustainability in the defined case study. A key frequently addressed principle in literature is "Population Density", which importance stems from its effect on the level of vibrancy in the public realm, viability of services within neighborhoods, and the overall quality of life (Barton 2000; Dempsey et al. 2010; Udell et al. 2014). Still, higher than needed population density might negatively contribute to people's perception of urban spaces and the quality of the built environment (Norhafizah et al. 2015). Therefore, population density needs to be within certain limits that preserve the liveliness of the public realm and the viability of services (Bramley et al. 2010; Dempsey et al. 2012; Mouratidis 2019). Julie Campoli in her book "Made for Walking", brought up the example of American cities in early $19 \mathrm{~s}$, in which a density of $18,000 \mathrm{ppsm}(\approx 69.5 \mathrm{pph})$ could afford the people's needs within their walking distances; and suggests a minimum population density threshold of $12,000 \mathrm{ppsm}(\approx 46.3 \mathrm{pph})$ for this aim (Campoli 2012). Meanwhile, Barton suggested a gross population density of 40 to $50 \mathrm{pph}$ as the density value by which the travel distances could be minimized (Barton 2000).

On the other hand, 'Urban Compactness' is a second indicator for density. It is usually measured by Floor Area Ratio (FAR) simply calculated by dividing the total builtup areas on the total neighborhood plot area. The more the value of the FAR, the more compact is the urban form of the neighborhood.

The second key social sustainability principle is "Accessibility" of the neighborhood amenities and services by its residents. As commonly known, Accessibility is about these destinations being reached within a walkable distance and through a defined, safe, convenient, and welldesigned walkways and or cycling lanes. Accessibility entails that the locally provided amenities and services are accessible for all people of different ages, genders, ethnicities, social strata, physical abilities, etc. (Carmona et al. 2003; Bramley et al. 2010; Wang et al. 2015, 2017).

The third influential principle is the provision of diversified mobility options for reaching local destinations by walking, cycling, and public transport. This would encourage restraining private car movements and thus help enhance the quality of the built environment and people health (Ferguson and Woods 2010; Leyden 2003; Berg et al. 2017; Jabareen 2006; Furlan et al. 2019).

Spatial "Integration" of the urban morphology of the neighborhoods is the fourth essential social sustainability principle because it improves the freedom of movement and choice, while allowing a mutually supportive role among different sections of the neighborhood's urban form (Carmona et al. 2003). When a well-integrated neighborhood is also spatially integrated with its surroundings, people can approach services and facilities provided in the neighboring communities to meet their missing needs.

"Choice and Diversity" is the fifth social sustainability principle, through which a set of diverse, well-designed, efficiently provided, and accessible choices of amenities and services are provided in the neighborhood (Makarewicz and Németh 2018; Williams et al. 2010). Moreover, access to diverse choices for housing types is as essential requirement because it helps meeting different housing needs of different strata of the society (i.e. different age groups, income levels, etc.). Diversity of housing types within a neighborhood allows the formation of a socially rich, vibrant, and inclusive community that is not segregated from the rest of the society (Karji et al. 2019; Smith 2011; Wassenberg and Dijken 2011; Zaina et al. 2016). Furthermore, provision of different jobs opportunities within the neighborhood is an essential social sustainability indicator for this principle. This does not only decrease the residents' need for commuting to work, but this would also help improve the life of people economically, especially those who for some reason or another are bound to their localities (Barton 2000; Bramley et al. 2010). All the above-mentioned issues make "Choice and Diversity" for mobility, services, housing, and local jobs, a key aspect for social sustainability in urban neighborhoods. To efficiently achieve this principle in a neighborhood, the sixth social sustainability principle of "Mixed-Use" pattern of development is fundamental, where a diversified land-use configuration can afford effective provision of various housing types, amenities, services, and movement options. This ultimately leads to a lively public realm within which people are encouraged to engage in daily social interactions (Barton 2000; Mouratidis 2018; Nabil and AbdEldayem 2015; Putnam 2000; Sung and Lee 2015).

"Environmental Quality" is the seventh essential principle for attaining a socially sustainable neighborhood. It is about fulfilling the need for a welcoming, safe, secure, and visually pleasant environment equipped with adequate physical elements that allow people to stay and enjoy it (Holland et al. 2007; 
Wassenberg and Dijken 2011; Van Dyck et al. 2011; Azmi and Karim 2012). The different aspects of 'human comfort' constitute the most important indicators of the environmental quality principle including: physical comfort, psychological comfort, thermal comfort, and visual comfort (Holland et al. 2007; Bramley et al. 2010). "Safety" and "Security" are also enumerated as two important and key principles of a socially sustainable environment (Newman 1996; Un-Habitat 2007; Welle et al. 2015). Safety, the eighth social sustainability principle, is achievable when the appropriate design and planning measures are taken to prevent non-criminal incidents (i.e. an unintended car-human accident especially by addressing streets' layouts). Meanwhile, Security, the ninth principle, could be achieved when the urban form characteristics and land-use configuration of the neighborhood help prevent criminal incidents (i.e. theft and assault through encouraging people's presence in its public realm). Such presence enhances community surveillance and can be encouraged through achieving safe and pleasant trips to accessible high-quality destinations and/or encouraging stay in these destinations.

Finally, "Social Capital" is claimed as an important social sustainability principle that can be identified when social interactions and collective activities are taking place on a regular basis within the neighborhood. Such interactions create and intensify the sense of trust, belonging, and satisfaction among the community members (Leyden 2003; Adriaanse 2011; Wood et al. 2008; Marans and Couper 2000; Hassen and Kaufman 2016). The above-mentioned social sustainability urban qualities such as walkability, integration, social mix, safety, security, are positively contributing to social capital in urban neighborhoods. Table 1 concludes these social sustainability principles and their relevant indicators. The last column of this table is allocated for the proposed assessment Integrated Multi-Tools, as discussed in the following section.

While the research focuses its attention on the mentioned above social sustainability principles and their related indicators, as they are the most related to the investigated problem, still it is admitted that, as a research limitation, the other essential social sustainability principles have not been fully covered, in particular, those related to the theme of equity, in its various aspects including class, ethnic, gender, etc. (de Geus 1999; Harris and Goodwin 2001; Dillard et al. 2009; Eizenberg and Jabareen 2017). A dedicated further research is needed to investigate these essential pillars of social sustainability on urban sustainability.

\section{A proposed Integrated Measuring Tools Method (IMTM) for assessing social sustainability indicators in exiting neighborhoods}

Some urban computer-based analytical techniques, such as the recently developed Urban Modeling Interface (UMI) and the well-established space syntax packages such as DepthmapX, seem to be able to bridge the experienced gap of the assessment of social sustainability indicators and principles in urban neighborhoods through adding more insights into the performance of their morphologies and spatial characteristics. UMI is a plugin for Rhinoceros 6 software that is designed by the Sustainable Design Lab at the MIT to assess the environmental performance of neighborhoods, including walkability and bikeability. The UMI builds a travel network model for the urban network configuration and the location of houses and amenities. Then, it uses Dijkstra's algorithm to perform shortest-path calculations giving walkability and bikeability scores to each location, ranging between 0 and 100 . While the 'distance' is the primary factor in the scoring process, the street intersection densities and the average block length are also considered as normalizing factors. The maximum walkability and bikeability scores are given to a house if its distance to the locally provided amenities do not exceed quarter a mile. After that, the scores gradually reduce until a $12 \%$ penalty is implemented at 1-mile distance. As the distance increases, a relatively steep decline in score ends up with receiving 0 when the distance reaches to 1.5 miles and farther (de Geus 1999).

The other tool, DepthmapX, is a spatial analysis platform designed for studying social processes within different scales of the built forms; aiming at deriving variables that may have social significances. The software was first developed more than two decade ago, and then has been gradually developed by at Space Syntax Laboratory at the Bartlett School of Architecture, University College London, UK. DepthmapX is utilized in this research for its ability to carry out spatial Integration analysis and Step Depth (shortest path) analysis. The Integration analysis evaluates the potential accessibility of each segment of the urban mobility network as a destination for movement from the other segments of the network. Meanwhile, the Step Depth analysis helps study the actual accessibility of certain segments based on their 'metric' distances from the other segments in the urban mobility network (Harris and Goodwin 2001).

The proposed 'Integrated Measuring Tools Method' (abbreviated as IMTM in this research) consists of both quantitative and qualitative techniques as relevant to each identified social sustainability indicator shown in Table 1. Besides the urban form quantitative computational tools of DepthmapX and UMI V.2 plugin in Rhino 
Table 1 The conceptual framework for social sustainability in urban neighborhoods and the assessment through the proposed 'Integrated Measuring Tools Method' (IMTM)

\begin{tabular}{|c|c|c|c|}
\hline & Principles & Indicators & $\begin{array}{l}\text { Assessment } \\
\text { integrated Multi- } \\
\text { Tools }\end{array}$ \\
\hline 1 & Density & Population density (between 40 and 50 pph) and urban compactness (FAR) & $\begin{array}{l}\text { Map analysis } \\
\text { UMl }\end{array}$ \\
\hline \multirow[t]{3}{*}{2} & \multirow[t]{3}{*}{ Accessibility } & \multirow{2}{*}{$\begin{array}{l}\text { (Services and facilities are located within } \\
\text { walkable and bikeable distances through } \\
\text { well-defined pathways/cycling lanes) }\end{array}$} & $\begin{array}{l}\text { UMI } \\
\text { Field observation }\end{array}$ \\
\hline & & & $\begin{array}{l}\text { UMI } \\
\text { Field observation }\end{array}$ \\
\hline & & Services and facilities are accessible for everyone & Field observation \\
\hline \multirow[t]{6}{*}{3} & \multirow[t]{6}{*}{ Mobility } & $\begin{array}{l}\text { (A safe, connected and well-designed pedes- } \\
\text { trian and cycling infrastructure) }\end{array}$ & $\begin{array}{l}\text { Field observation } \\
\text { Map analysis }\end{array}$ \\
\hline & & Bikeability & $\begin{array}{l}\text { Field observation } \\
\text { Map analysis }\end{array}$ \\
\hline & & Availability of accessible and cost-effective public transport & $\begin{array}{l}\text { Secondary resources } \\
\text { Map analysis } \\
\text { DepthmapX }\end{array}$ \\
\hline & & Restrained private car traffic (prioritization of non-privatized modes of movement) & $\begin{array}{l}\text { Field observation } \\
\text { Map analysis }\end{array}$ \\
\hline & & Decentralized provision of services & $\begin{array}{l}\text { Map analysis } \\
\text { UMl }\end{array}$ \\
\hline & & Transit oriented development (TOD) & $\begin{array}{l}\text { Map analysis } \\
\text { DepthmapX }\end{array}$ \\
\hline \multirow[t]{3}{*}{4} & \multirow[t]{3}{*}{ Integration } & Spatial connectivity with adjacent neighborhoods & $\begin{array}{l}\text { DepthmapX } \\
\text { Field observation }\end{array}$ \\
\hline & & Spatial connectivity of the neighborhood's street network & DepthmapX \\
\hline & & $\begin{array}{l}\text { Mutual supporting role among the neighborhood and its surrounding neighborhoods (in terms } \\
\text { of provided amenities and services) }\end{array}$ & Map analysis \\
\hline 5 & Choice and Diversity & $\begin{array}{l}\text { Diverse range of high-quality services, housing types, non-car-based jobs, open spaces, and } \\
\text { modes of mobility }\end{array}$ & $\begin{array}{l}\text { Map analysis } \\
\text { Field observation }\end{array}$ \\
\hline \multirow[t]{3}{*}{6} & \multirow[t]{3}{*}{ Mixed-use } & Mixed land-use of the neighborhood plan & Map analysis \\
\hline & & Availability of quality open spaces that can accommodate various social and commercial activities & $\begin{array}{l}\text { Field observation } \\
\text { Map analysis }\end{array}$ \\
\hline & & Ability to undertake multi-purpose trips & Map analysis \\
\hline 7 & Environmental Quality & Physical, psychological, thermal, and visual comfort & Field observation \\
\hline \multirow[t]{6}{*}{8} & \multirow[t]{6}{*}{ Safety } & Avoiding urban sprawl & $\begin{array}{l}\text { UMl } \\
\text { Map analysis }\end{array}$ \\
\hline & & Calmed road traffic & Field observation \\
\hline & & Inclusive safety measures for pedestrians and cyclists & $\begin{array}{l}\text { Field observation } \\
\text { Map analysis }\end{array}$ \\
\hline & & Safe and integrated network for pedestrians & $\begin{array}{l}\text { Field observation } \\
\text { Map analysis }\end{array}$ \\
\hline & & Safe and integrated network for cyclists & $\begin{array}{l}\text { Field observation } \\
\text { Map analysis }\end{array}$ \\
\hline & & Safe access to public transport nodes & $\begin{array}{l}\text { Field observation } \\
\text { Map analysis }\end{array}$ \\
\hline \multirow[t]{4}{*}{9} & Security & Avoiding dead-end streets & Map analysis \\
\hline & & Encouraged urban surveillance & Field observation \\
\hline & & Dwelling units occupied mostly by owners & Secondary resources \\
\hline & & Rent/property price (social stratum) & Secondary resources \\
\hline
\end{tabular}


Table 1 (continued)

\begin{tabular}{|c|c|c|c|}
\hline & Principles & Indicators & $\begin{array}{l}\text { Assessment } \\
\text { integrated Multi- } \\
\text { Tools }\end{array}$ \\
\hline \multirow[t]{4}{*}{10} & \multirow[t]{4}{*}{ Social capital } & $\begin{array}{l}\text { Available social gathering nodes (regular occurrence of social interactions leading to social } \\
\text { networks) }\end{array}$ & $\begin{array}{l}\text { Field observation } \\
\text { Map analysis }\end{array}$ \\
\hline & & Encouraged people encountering (through walking) & $\begin{array}{l}\text { UMI } \\
\text { Map analysis } \\
\text { Field observation }\end{array}$ \\
\hline & & Distinctive urban design and high-quality services and facilities (increase sense of belonging) & $\begin{array}{l}\text { Field observation } \\
\text { Map analysis }\end{array}$ \\
\hline & & Community participation (increases trust) & Secondary resources \\
\hline
\end{tabular}

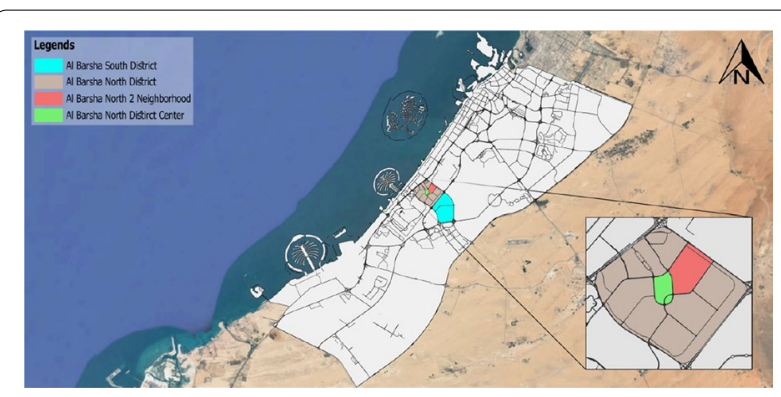

Fig. 1 Al Barsha North 2 location map (https://earthengine.googl e.com/timelapse/)

5 software, the proposed method encompasses relevant qualitative tools of the Maps Analysis, Field Observations and Secondary Resources (Table 1).

\section{Al Barsha North $\mathbf{2}$ as a selected case study}

Al Barsha is a residential area located near the center of Dubai city and at the south-eastern side of its downtown. It is divided into two residential districts at the northern and southern sides of Al-Khail Road (Fig. 1).

The greater part of Al Barsha area-more than twothird of it-is allocated for the local government's subsidized housing program for Emirati citizens which is managed and developed by the Mohammed Bin Rashid Housing Establishment. The northern district, called $\mathrm{Al}$ Barsha North, is the earlier phase of this development and was primarily formed by the six single-family subsidized housing neighborhoods located around the Al Barsha North district center. Al Barsha North 2, as part of $\mathrm{Al}$ Barsha North District, was established in 2000 and many of its planned serviced were incrementally developed between 2000 and 2010 (including a mosque, schools, shops, a neighborhood park, etc.) (Fig. 2). The cluster parks have not been developed yet.

The total area of Al Barsha North 2 the neighborhood is about 200 hectares and it is planned to accommodate 691 single-family housing units in a back-to-back plots format and with a plot area of $30 \mathrm{~m} \times 45 \mathrm{~m}$ and an estimated total population of 4396 persons (7.4 persons per dwelling (Dillard et al. 2009)). The urban form of the neighborhood is composed of 4 clusters positioned around a neighborhood center, while having a local center within each of the clusters (Fig. 2). Each local center is supposed to incorporate a number of amenities in accordance with the size of the section it belongs to. Accordingly, a park or a pocket garden, a mosque, and a certain number of shops and amenities are, or expected to be, provided in every local center. Meanwhile, the diversity and the scale of the provided services vary in the whole $\mathrm{Al}$ Barsha area from cluster local centers to the neighborhood centers and to the district center (Fig. 2).

Given the fact that almost the same planning approach has been followed in many other Emirati neighborhoods in Dubai, so Al Barsha North 2 can be regarded as a representative housing development of its kind in the local context of Dubai. This would make this case study a reliable and representative one for studying social sustainability on the neighborhood scale and therefore the research analysis results could be generalized for other Emirati neighborhoods in the city.

\section{Utilizing the Integrated Measuring Tools Method (IMTM) in assessing social sustainability in AI Barsha North 2}

In this section, the results of the assessment of the indictors of the specified social sustainability principles in $\mathrm{Al}$ Barsha North 2 are presented. The assessment was carried out utilizing the defined Integrated Measuring Tools Method (IMTM), as shown in Table 1.

\section{Density}

For assessing density, the Map Analysis was utilized to calculate the population gross density. As mentioned above, the housing typology of Al Barsha North 2 is 


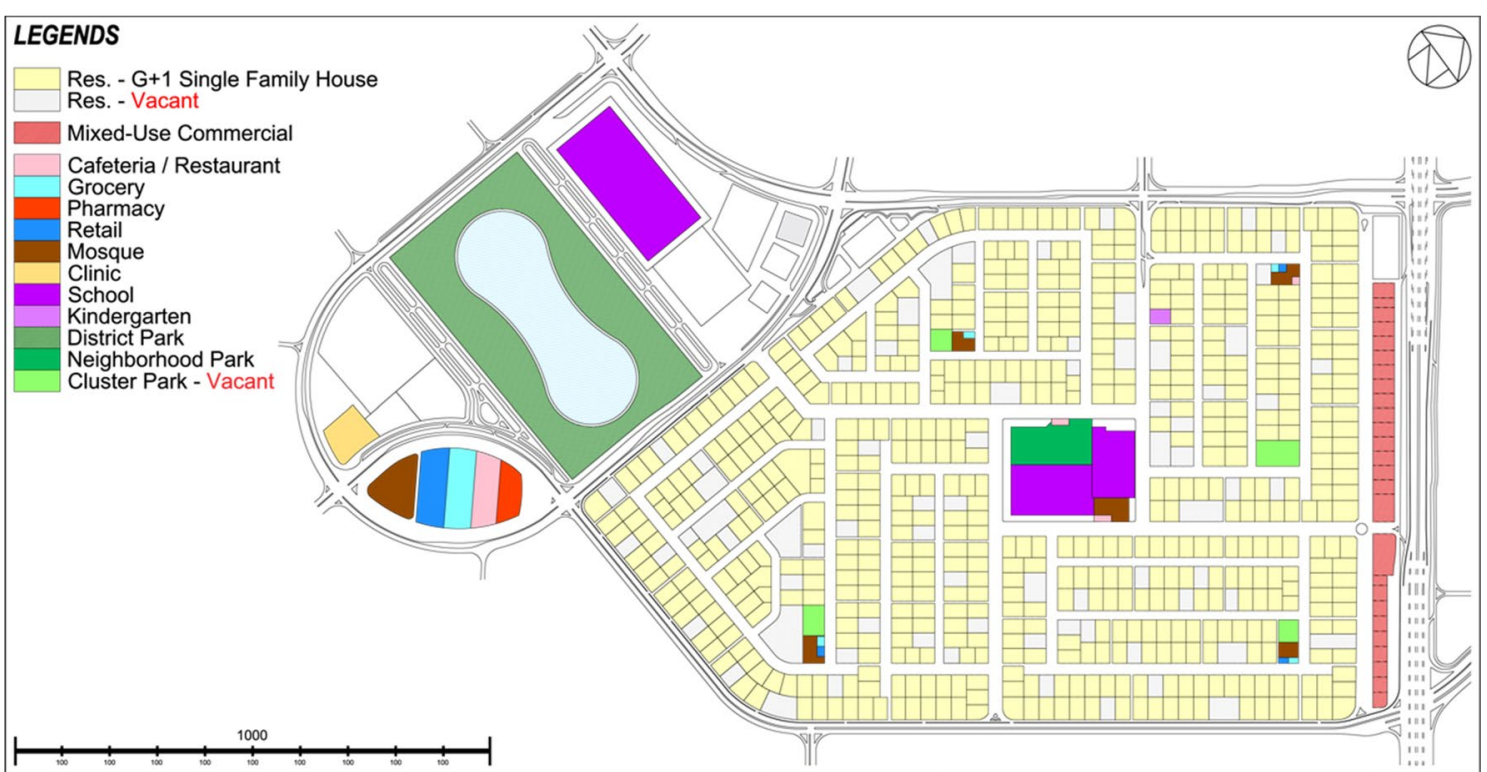

Fig. 2 Al Barsha North 2 Land-Use Plan, and Al Barsha district center

single-family detached houses. The total population was calculated by simply multiplying the number of houses by the average family size of 7.4 persons. Dividing the total population by the total neighborhood area indicated that the gross population density is considerably low with about $22 \mathrm{pph}$, especially if compared with the gross population density of 40 to $50 \mathrm{pph}$, as suggested by the conceptual framework. Additionally, the Floor Area Ratio (FAR) of the neighborhood, as a measure of its urban compactness, was calculated through the UMI plugin. It reached only 0.32 , which represents a significantly dispersed urban form. Therefore, it could be claimed that the neighborhood has 'Poorly Achieved' this principle.

\section{Accessibility}

The UMI plugin was used to assess walkability through Walkability Scoring that ranges between 0 and 100 . The result, as shown in Fig. 3, indicates that $\mathrm{Al}$ Barsha North 2 is barely walkable according to the benchmarking (Loo et al. 2017) (Fig. 4). As revealed by the Field Observations also, the neighborhood is lacking a safe, well-designed, well-maintained, and well-connected

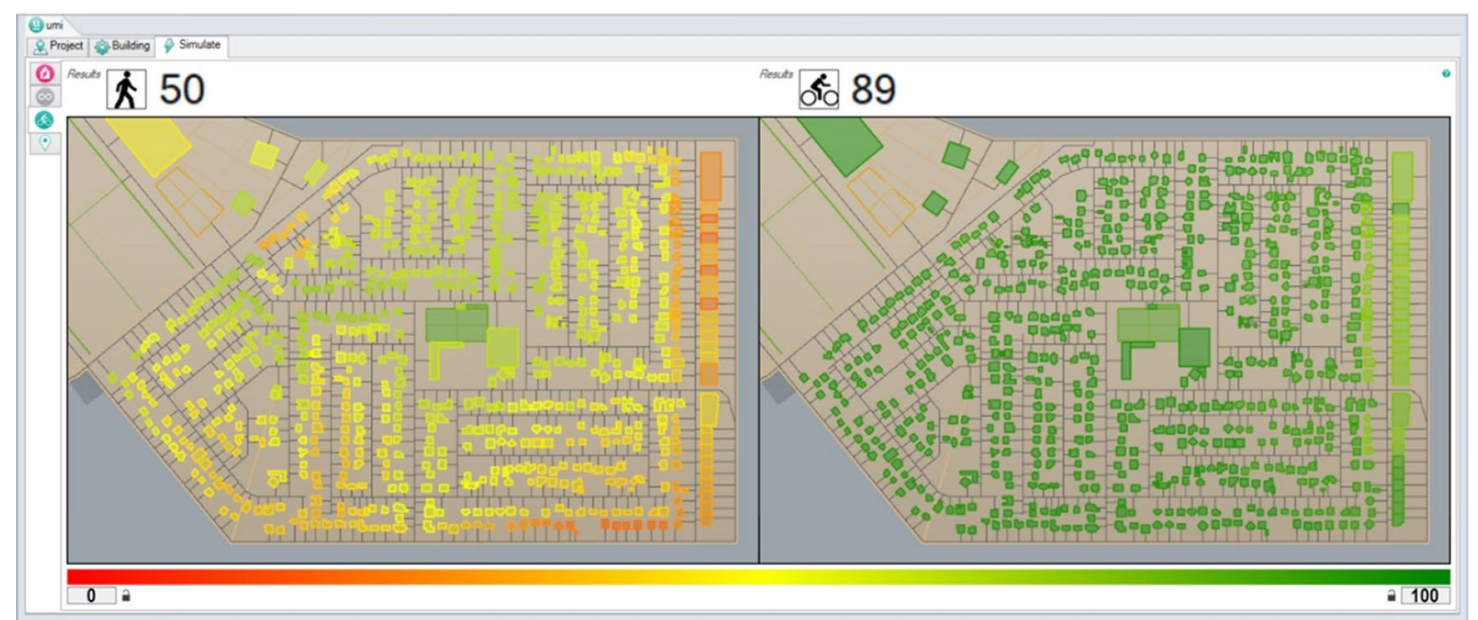

Fig. 3 Walkability and bikeability analysis performed using UMI tool 


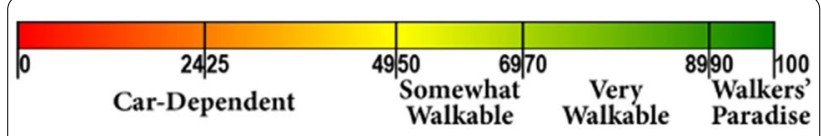

Fig. 4 Walkability benchmarking (Rakha and Reinhart 2013)
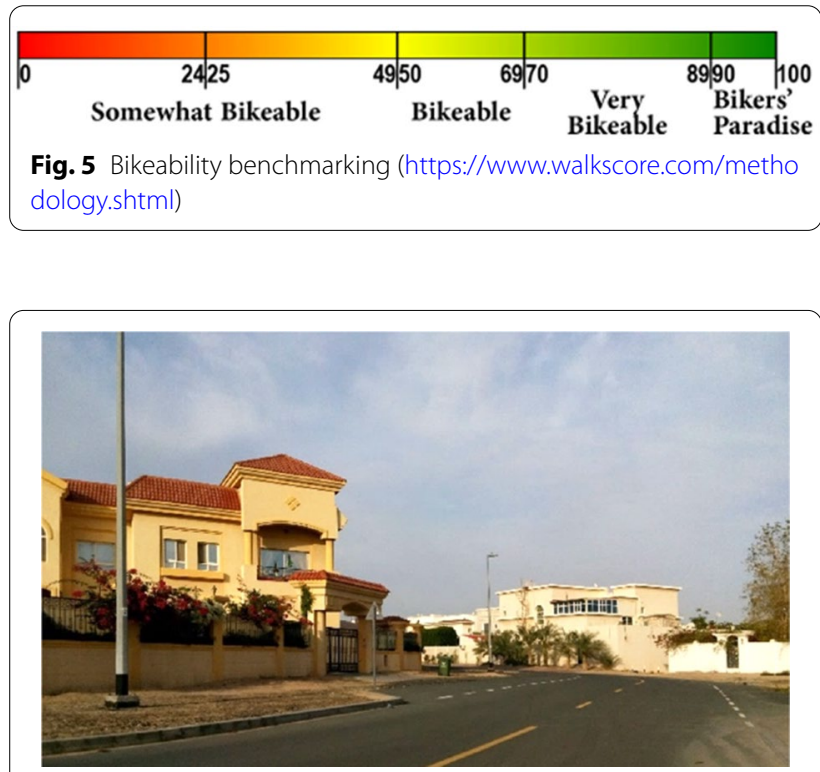

Fig. 6 Example 1 for the lack of a safe, well-designed, well-maintained, and well-connected pedestrian realm/Lack of cycling infrastructure

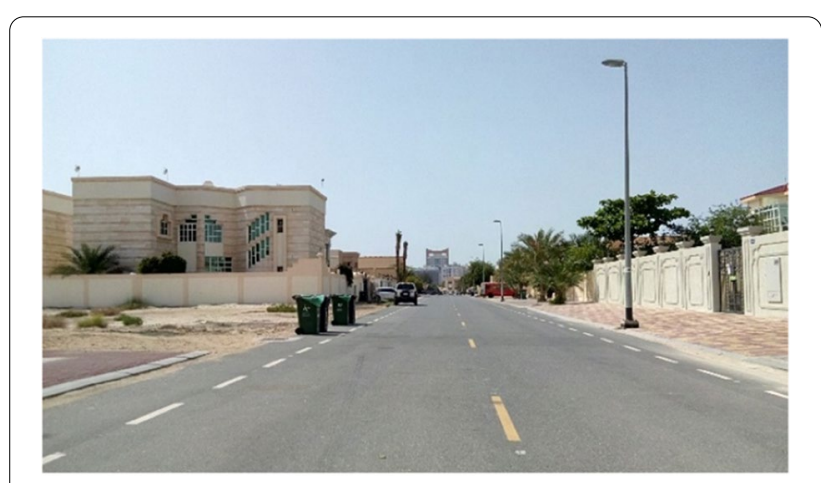

Fig. 7 Example 2 for the lack of a safe, well-designed, well-maintained, and well-connected pedestrian realm/Lack of cycling infrastructure

pedestrian realm (Figs. 6 and 7), and it can be considered as 'car-dependent'. As for the bikeability, despite the good results by UMI simulation (Fig. 5), the Field Observations showed total absence of dedicated cycling lanes (Figs. 6 and 7), which compromises the safety of the cyclists.

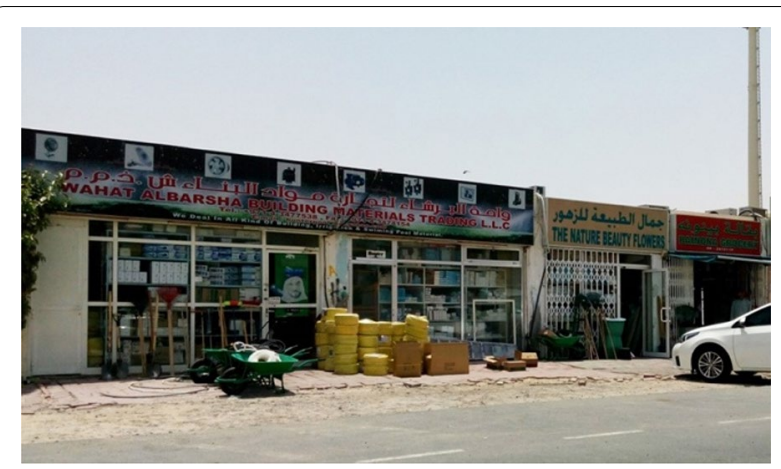

Fig. 8 Unpaved and uneven access to some retail shops

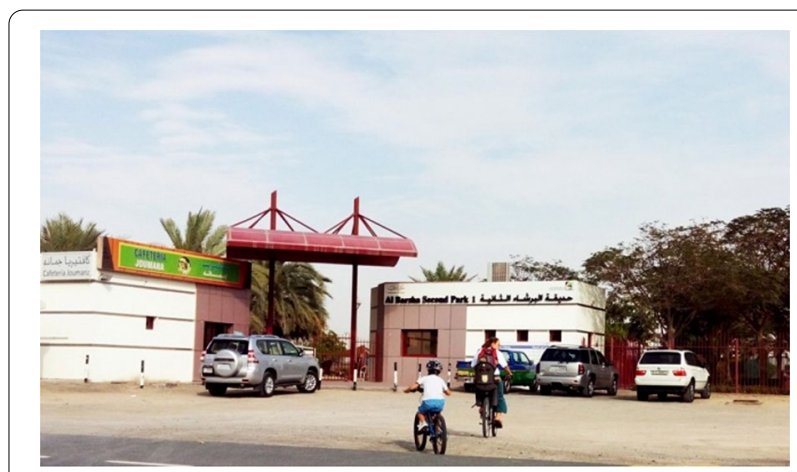

Fig. 9 Unpaved, uneven, and sandy entrance of the neighborhood park

On the other hand, through Field Observations, it was noticed that many of the unpaved and poorly maintained entrances of the neighborhood amenities, including the park and some of the shops (Figs. 8 and 9), hinder accessibility especially for the elderly and disabled people. So, these deficiencies prevent the neighborhood from achieving a satisfactory degree of accessibility that could have boost its social sustainability and therefore the Accessibility principle is "Poorly Achieved".

\section{Mobility}

As evident from the Field Observations and the Map Analysis, the pedestrian network is not well considered, and the cycling network is entirely missing in the neighborhood. This discourage people to select "walking" and "cycling" as reliable modes of mobility. On the other hand, despite being affordable to use, the provided public transport in $\mathrm{Al}$ Barsha North 2 neighborhood is very limited to only two peripheral bus stops (Fig. 10). According to the website of the Road and Transport Authority (RTA) in Dubai (Eizenberg and Jabareen 2017), one bus stop services two bus lines F30 and 37 and the second services only one line F33. The F30 and 37 bus lines are 


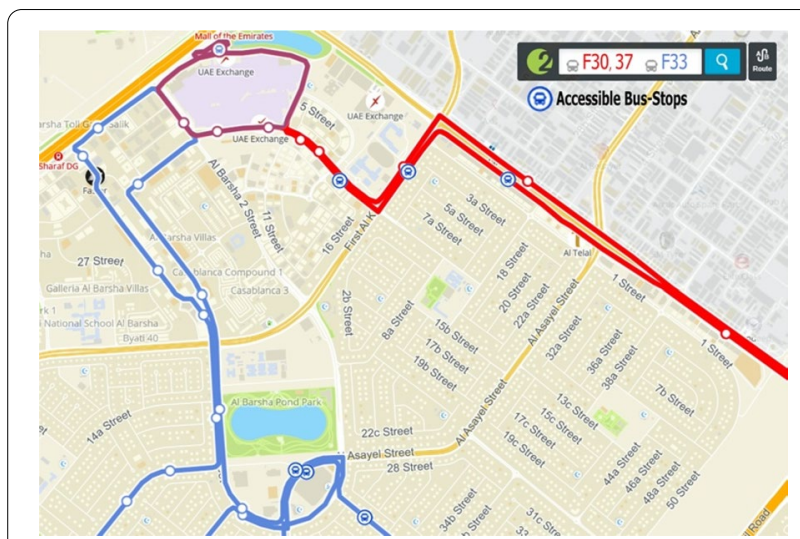

Fig. 10 Public transport provided in Al Barsha North 2 (https://2gis. ae/dubai)

collectively picking up passengers at almost every 20 to 30 min, while the F33 bus line is picking up passengers at every 20 to $30 \mathrm{~min}$ during the daytime and at every 50 to $60 \mathrm{~min}$ by the early evening and night times. Additionally, the Step Depth analysis of the DepthmapX software showed long walking distances to the two bus stops (Fig. 11) which reached to almost $1 \mathrm{~km}$ in average.

Field Observations and the Map Analysis of the neighborhood's land-use (Fig. 2) clearly illustrate the permeability of the car movement network and the absence of restrained private car traffic. Moreover, both of the Map Analysis and the UMI simulation (Figs. 2 and 3) exposed the relatively decentralized localization pattern of the amenities and services in the planning of the neighborhood thanks to the allocated service centers in its urban form. Still, the non-diversified types of services and amenities, associated with the discussed above concerns of inappropriate walking distances and infrastructures are discouraging residents to abandon using their own cars to move around.

Finally, through the Map Analysis (Figs. 2 and 10), and Step Depth analysis of DepthmapX (Fig. 11), it is evident that the urban form of this neighborhood is not considering the Transit Oriented Development (TOD) design pattern. So, the analysis of the various indicators of the principle of Mobility rendered the neighborhood "Poorly Achieving" the social sustainability mobility-related qualities.

\section{Integration}

DepthmapX 'Integration' analysis revealed reasonable degree of spatial connectivity of the neighborhood's street network (Fig. 12). Still, the same analysis for the neighborhood with one of its adjacent neighborhoods disclosed much less degree of spatial integration (Fig. 13). Field Observations affirmed the lack of integration within the district, mainly due to the wide and high-speed peripheral streets separating the district's neighborhoods (Fig. 14). This has made the movement between Al Barsha North 2 and its adjacent neighborhoods extremely difficult without private cars.

On the other hand, the Map Analysis as shown in Fig. 15 disclosed the limited amenity types provided in the centers of all neighborhoods in Al Barsha North district, including the case study neighborhood. This has significantly undermined the mutual supporting role among the neighborhood and its surrounding neighborhoods in terms of the provided services and amenities. So, all in all, except for some degree of spatial connectivity of the neighborhood's street network, other Integration indicators are not indicating

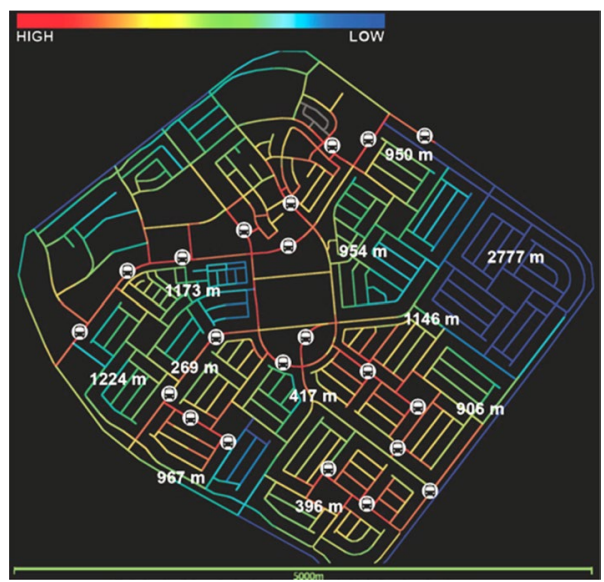

Fig. 11 Bus-Stops distances to residents in the whole Al Barsha North District, calculated by the DepthmapX tool

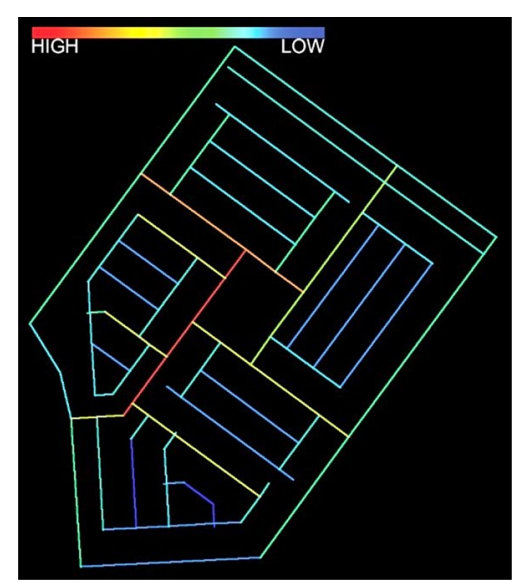

Fig. 12 Spatial integration of the neighborhood's street network simulated by DepthmapX 


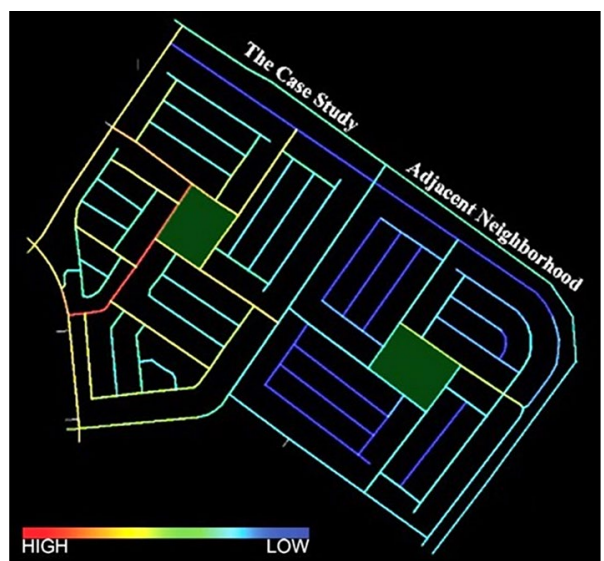

Fig. 13 Spatial integration between the neighborhood's street network and its adjacent neighborhood's networks as simulated by DepthmapX

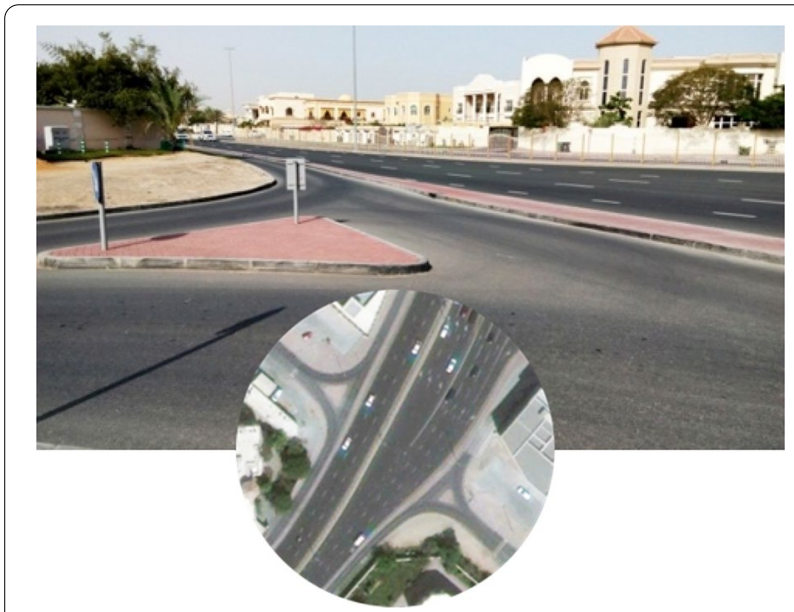

Fig. 14 The arrangement of peripheral streets that prevents easy access from/to surrounding neighborhoods

a socially sustainable neighborhood in this regard and therefore the overall principle of Integration is "Poorly Achieved".

\section{Choice and diversity}

As discussed above, through the utilization of Map Analysis and Field Observations tools, it could be easily claimed that the neighborhood offers a considerably limited range of high-quality services, housing types, non-car-based jobs, open spaces, and modes of mobility. One exception is the neighborhood's and district's parks which have achieved some degree of highquality open and recreational facilities (Figs. 16 and 17). So, this principle is "Poorly Achieved".
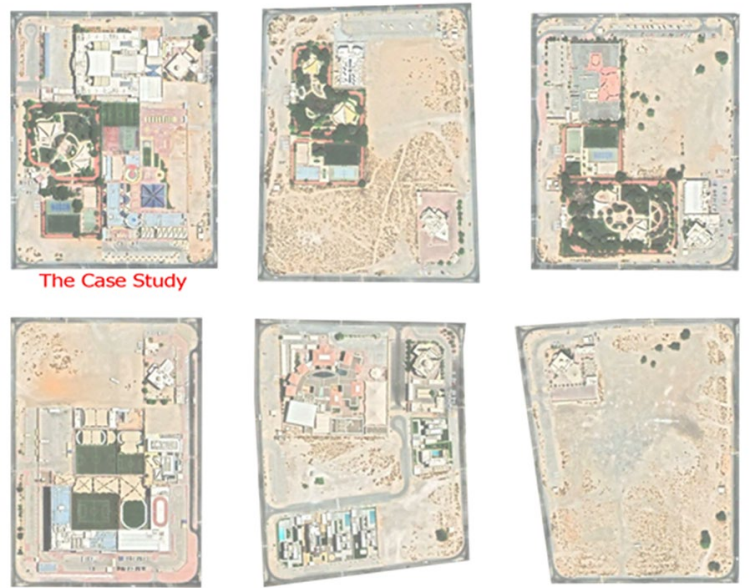

Fig. 15 Condition of neighborhood centers across the Al Barsha North District (https://earthengine.google.com/timelapse/)

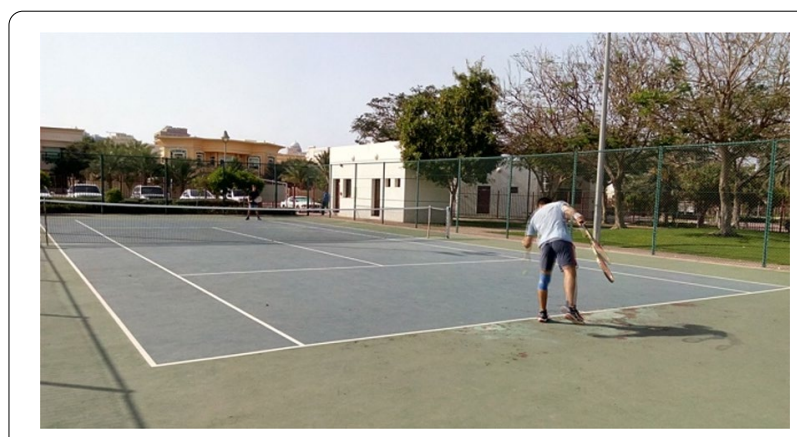

Fig. 16 Tennis court at Al Barsha North 2 Neighborhood Park - quality environment provided for residents

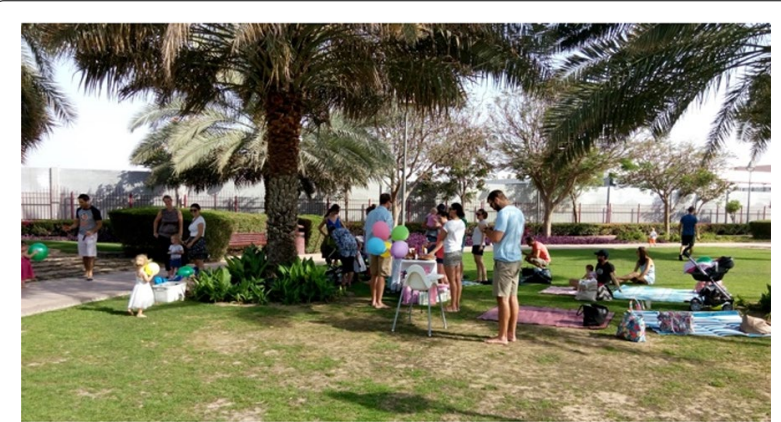

Fig. 17 The high-quality environment at the neighborhood park encourages collective activities and interactions

\section{Mixed-use}

As shown in Fig. 2, the Map Analysis easily reveals the lack of mixed land use in the planning of Al Barsha North 2 . The only one type of developed housing actually has 
hindered mixing other retail, commercial and administrative uses with the residential use. Both of the Map Analysis and Field Observations exposed the availability of quality open spaces, albeit not in a sufficient manner. Map Analysis also divulged limited ability to undertake multi-purpose trips to the neighborhood and district centers where many services and facilities are still absent. The lack of mixed use has deprived the neighborhood from a vital principle of social sustainability as it hinders the opportunities for social interaction and communication in addition to increasing the reliance on private cars for commuting. Therefore, the principle is "Partially Achieved" in the neighborhood.

\section{Environmental quality}

Field Observations enabled assessing signs of physical and thermal comfort. The lack of sitting benches, shading devises, and landscape weather mitigating elements, besides the extensive use of pavement and concrete blocks in sidewalks, inevitably lead to physical and thermal discomfort (Figs. 6, 7, 18 and 19). Regarding visual comfort, the good appearance of most houses with their usually well-maintained fences and gates, together with the overall cleanness of the streets, have created a generally accepted level of visual and psychological comforts for the neighborhood's residents. Finally, the observed shortcomings associated with the deteriorated-or even absent-pedestrian and cycling infrastructures, the long walking distances, the prioritized private car movement, and the spiritless public realm, negatively affect the level of psychological comfort. So, all in all, the urban form in Al Barsha North 2 is not fully maintaining various types of comfort in a socially sustainable manner and this renders the principle as "Partially Achieved".

\section{Safety}

Both the UMI simulation and the Map Analysis showed the negative effect of the neighborhood's urban sprawl on safety. This dispersed urban form has resulted in long

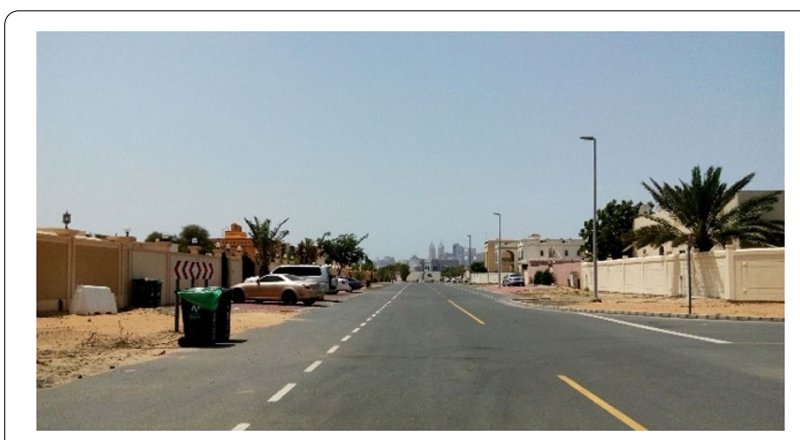

Fig. 18 Low quality of pedestrian network, Example 1

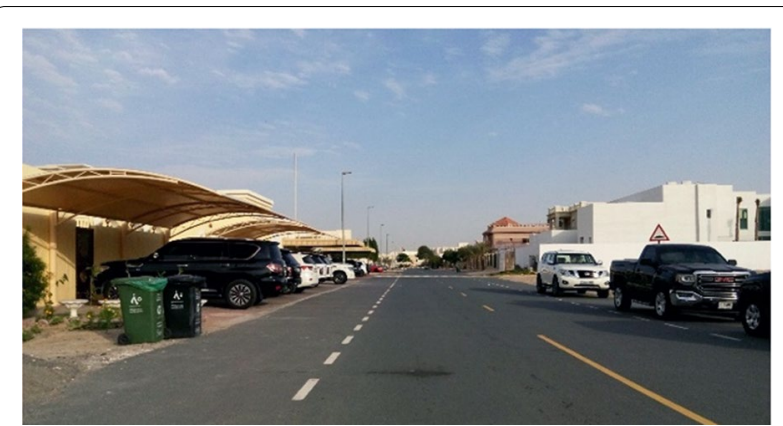

Fig. 19 Low quality of pedestrian network, Example 2

walking distances and wide streets which have prioritized the car traffic and accordingly increased the private cardependency. As a result, safe accesses to local services and public transport nodes have been adversely affected. Field Observations and Map Analysis identified the lack of dedicated, prioritized, well-maintained, integrated, and protected pedestrian and cycling pathways. This, for sure, has stemmed unsafe conditions that increased the possibility of road accidents. The same status applies to the safety measures of the pedestrian/cyclist's accesses to bus stops. Therefore, it could be claimed that Al Barsha North 2, has not satisfied the safety principle of social sustainability and it is considered "Poorly Achieved".

\section{Security}

The Map Analysis of the urban form of Al Barsha North district as a whole, including Al Barsha North 2 neighborhood, illustrates that dead-end streets are partially found in every housing cluster in the neighborhood (Fig. 20). As revealed from Field Observations above, the urban form itself does not also encourage community urban surveillance as people are not encouraged to walk or gather in the streets and/or open spaces. Moreover, the high and solid external fences of the houses prevent windows' overlooking to streets and open spaces.

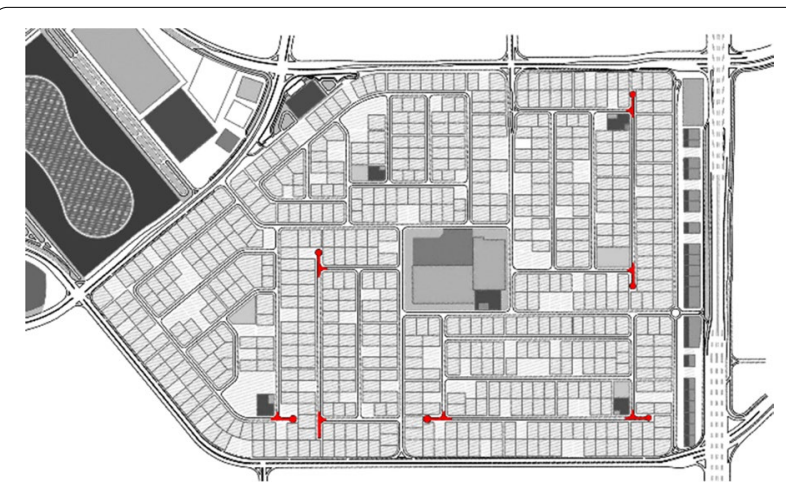

Fig. 20 The dead-end streets (marked in red) in Al Barsha North 2 
On another front, the neighborhood has a high owneroccupancy rate because the neighborhood is developed as a subsidized Emirati housing project which obliges landlords to reside in the granted properties for a certain period of time. Also, as per the Dubai Land Department (Sustainable Design Lab 2013), the rent value of the houses in the neighborhood ranges between 145,000 and 297,000 dirhams per annum, depending on the area and the number of bedrooms (from 3 to 6 bedrooms). Consequently, the tenants, if any, would belong to the middle/ upper social stratum with its associated low crime-rates and thus the sense of security in this neighborhood will be normally high. Despite its overall good security condition, the urban form related characteristics of the neighborhood have "Partially Achieved" the indicators of the security principle of a socially sustainable neighborhood.

\section{Social capital}

The tools of Filed Observations and Map Analysis showed that the urban form has some potentials for creating social gathering nodes but unfortunately these nodes are not vivid enough. For example, the neighborhood's centers lack many of services and facilities that would encourage people to gather and meet. One exception is the neighborhood park, as discussed earlier, as it was a good case for showing how the high-quality open space could encourage social interactions and community activities, and therefore promotes vibrancy and improve social capital of the local community.

As discussed above also, through the UMI simulation, Map Analysis, and Field Observations, walkability is not encouraged in the neighborhoods, so this would decrease the change for residents' interaction and encountering. According to the conducted Field Observations, social interactions in the public realms of $\mathrm{Al}$ Barsha North 2 were rarely observable. Sense of belonging is another indicator for social sustainability that usually increases with the presence of distinctive urban design and highquality services and facilities. As revealed previously from the Field Observations and Map Analysis the urban design of the neighborhood relies on a repetition of identical housing clusters with minimal efforts excreted to achieve distinctiveness of living places. Finally, no evidence for community participation was found from the local authorities. This of course would not create the chance for mutual interaction and would consequently undermine the level of trust and the willingness for participation in collective activities among the local community members in the neighborhood. So, it could be concluded here that the principle of social capital has not been encouraged in the design of the neighborhood and therefore it could be claimed as "Poorly Achieved".

\section{Utilizing the IMTM in enhancing and validating social sustainability in AI Barsha North 2}

Social sustainability redevelopment guidelines and suggested actions

The conducted assessments using the IMTM revealed a variety of social sustainability related shortcomings associated with the urban form of $\mathrm{Al}$ Barsha North 2 neighborhood mainly including its mobility networks, land use, and the amenities' provision and localization. All of these aspects have hindered the attainment of the social sustainability principles in the neighborhood. Table 2

Table 2 Redevelopment guidelines and recommended actions for enhancing social sustainability in urban neighborhood

\begin{tabular}{|c|c|c|}
\hline & Design strategies/guidelines & Recommended actions \\
\hline 1 & Increasing density & $\begin{array}{l}\text { Applying infill strategy-taking advantage of vacant plots (increasing the FAR and the gross population } \\
\text { density to be from } 40 \text { to } 50 \text { pph) }\end{array}$ \\
\hline 2 & Redefining the land-use plan & Providing suitable locational distribution of a mixture of needed local services and amenities \\
\hline 3 & Diversifying housing types & Adding different sizes of apartments and housing units to the exiting mono housing category \\
\hline 4 & Integrating street networks & $\begin{array}{l}\text { Connecting the dead-end streets with nearest streets but for only pedestrian and cycling movements } \\
\text { Restraining car-movements }\end{array}$ \\
\hline 5 & Diversifying movement modes & $\begin{array}{l}\text { Adding cycling infrastructures } \\
\text { Improving pedestrian network } \\
\text { Improving access to public transport nodes }\end{array}$ \\
\hline 6 & Improving accessibilities & $\begin{array}{l}\text { Reconsidering access of people with special needs, elderly, etc } \\
\text { Improving quality of services } \\
\text { Enhancing walkability and bikeability }\end{array}$ \\
\hline 7 & Adapting urban landscape & $\begin{array}{l}\text { Mitigating the effect of the outdoor temperature (through various shading strategies) } \\
\text { Improving pedestrian walkways design } \\
\text { Improving street furniture (setting benches, etc.) }\end{array}$ \\
\hline 8 & $\begin{array}{l}\text { Enhancing and diversifying } \\
\text { Amenities and services }\end{array}$ & $\begin{array}{l}\text { Decentralizing services } \\
\text { Diversifying services } \\
\text { Improving quality of services }\end{array}$ \\
\hline
\end{tabular}


below suggests a set of strategies/guidelines for the redevelopment of $\mathrm{Al}$ Barsha North 2 neighborhood that are mainly addressing these identified concerns.

As shown in Table 2, the recommended actions for these guidelines were inspired by consulting some research works addressing urban redevelopment from the social sustainability point of view. These research works are usually asserting four main areas for improving social sustainability principles namely; density, land use, diversity, and modes of transport especially walkability. For enhancing density, infill is the commonly suggested action for urban densification. It is promoted as an effective and reliable solution for overcoming the low population density problem and its related symptoms such as the lack of vibrancy in the public realm and the unviability of services within the neighborhood (Alawadi 2017; Space Syntax Laboratory 2001; Abu Dhabi Urban Planning Council 2012; http://wojhati.rta.ae). The infill solution also involves the redefinition of the land-use, which is at the same time a major aspect of the urban form that needs to be dealt with when planning for redevelopment (http://wojhati.rta.ae; https://www.sim.gov. ae/Public/RentalIndexPage.aspx?lng=en). Through the application of infill and mixed land uses, the diversity aspect would also become conceivable where various housing types and diversified amenities could be introduced (Zaina et al. 2016). In coordination with the above actions, the integration of the movement networks and the enhancement of its infrastructure will decrease the travel distances and promote non-motorized modes of transport (Abu Dhabi Urban Planning Council 2012; Loo et al. 2017; Miller and Hoel 2002). Accordingly diversified and accessible modes of transport would be a necessity to realize a socially sustainable redevelopment of the neighborhood (Alawadi 2017; Zaina et al. 2016; http:// wojhati.rta.ae). The recommended actions are detailed in Table 2.

As detailed below, the defined redevelopment guidelines were used in developing a redevelopment scenario for Al Barsha 2 neighborhood, then testing it against the status quo of the neighborhood using the proposed IMTM. This has proved the effectiveness of the IMTM as a tool for both the assessment of social sustainability and validating the social sustainability redevelopment scenarios of urban neighborhoods.

\section{An IMTM-validated scenario for socially sustainable urban redevelopment of AI Barsha North 2}

The applied infill strategy has significantly increased the FAR of the neighborhood from 0.32 to nearly 0.70. Three types of infill actions in Al Barsha North 2 were considered. First is adding 59 plots with a minimum width of $30 \mathrm{~m}$, suitable for developing G+2 town houses that can accommodate 1105 persons. Second is adding 20 larger size plots that are suitable for developing G+4 apartment buildings with ground floor shops. These blocks can accommodate 2362 additional persons. Third is adding 26 plots for $\mathrm{G}+5$ mixed-use (residential-commercial) buildings with the G floors allocated for shops, the 1st and the 2nd floors allocated for offices, and the remaining 3 floors are allocated for residential use accommodating 1156 persons (Figs. 21 and 22). By assuming the current 'gross percapita floor area' in the neighborhood equals $90 \mathrm{~m}^{2}$, as

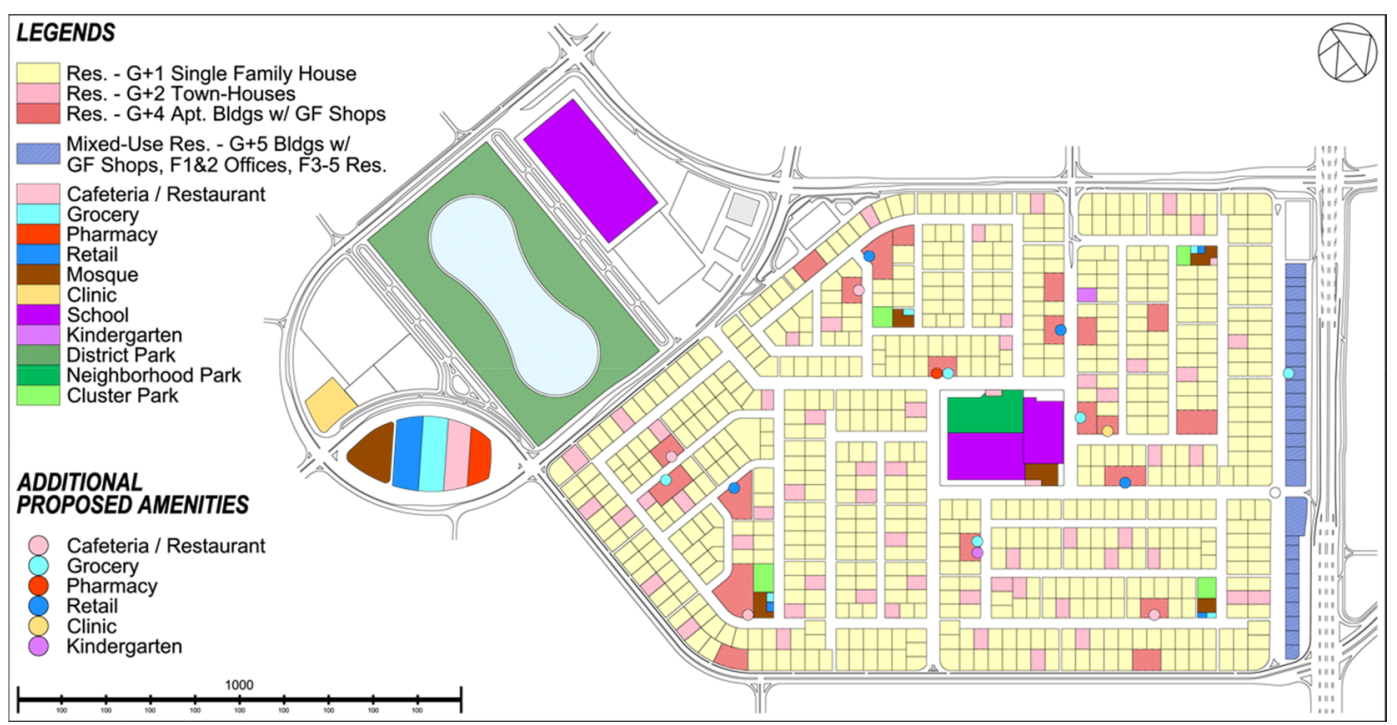

Fig. 21 Al Barsha North 2 redeveloped land-use plan 


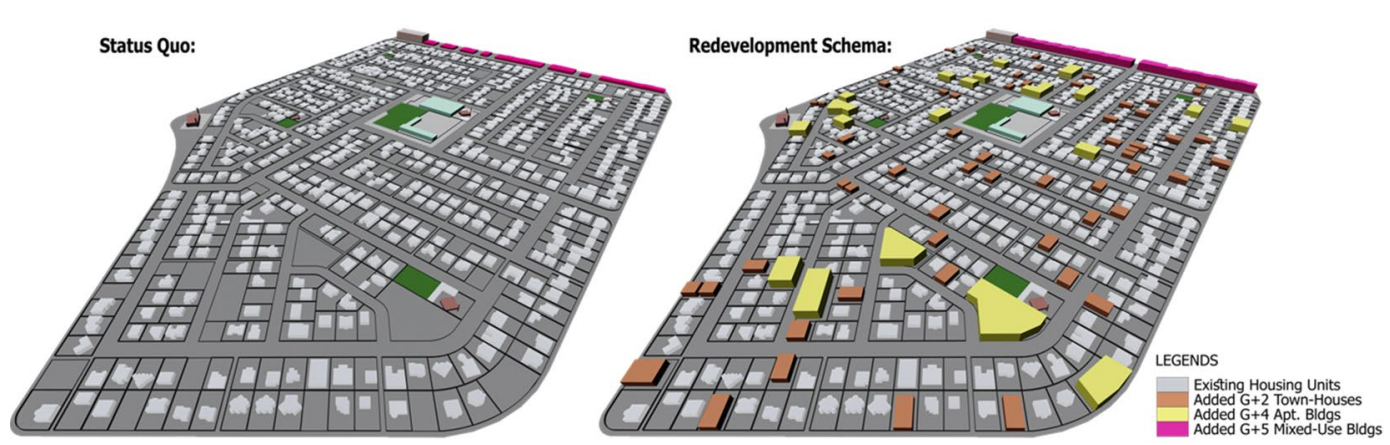

Fig. 22 Al Barsha North 2; the status quo vs. the redevelopment urban form

the basis for the calculations, the applied infill actions would help increase the population by additional 4623 persons, thus, increasing the capacity of the urban form to accommodate a population of 9019 within the same neighborhood overall urban area. As a result, the gross population density would reach $45.1 \mathrm{pph}$ that falls within the 40 to $50 \mathrm{pph}$ acceptable range.

Increasing density by this strategy would help enhance the social sustainability of the neighborhood, not only by ensuring the viability and the quality of provided amenities and services, but also by providing access to diverse housing options which will allow people of younger generations and relatively lower income levels to merge with the existing community, and hence build a socially dynamic and rich neighborhood. The adopted infill strategy required redefinition of the landuse plan through adopting a more decentralized and diversified pattern for the provision of amenities. This was achieved through allocating the ground floors of the added blocks for shops and amenities of the types that compensate for the missing community needs.

The increased types and numbers of amenities were informed by the status quo analysis in addition to the expected increase in needs due to the increased population density. As presented in Fig. 21, the location for the added amenities is proposed to be geographically covering the catchment areas as much as possible, bearing in mind that the only opportunity to locate the additional amenities is the ground floors of the apartment blocks. The resulting more compact urban form avails the provision of a greater number and more diversified amenities that meet the expected diversified needs of the community members in the redevelopment scenario. As a result, the distances between the houses/flats and the amenities will be decreased and accordingly the ability of the residents to undertake multi-purpose trips will be enhanced. This would result in significant improvement of walkability and bikeability in the neighborhood.
Because the improvement of walkability and bikeability in the urban form also requires (re)developing proper walking and cycling infrastructures, hence, it was necessary to redefine the streets' layouts and to provide a welldesigned and safe environment in which walking and cycling movements are prioritized over vehicular movements. The three types of streets in Al Barsha North 2, based on their widths, are the primary (about $30 \mathrm{~m}$ ), the secondary (about $24.4 \mathrm{~m}$ ), and the tertiary streets (about $19 \mathrm{~m}$ ) (Fig. 23). As already noticed in Figs. 6, 7, 18 and 19, much of the current streets' widths are allocated for cartraffic, whereas the existing pedestrian walkways are only confined to the relatively narrow and poorly maintained sidewalks of these streets.

While the noticeable wide driveways contributed to the unsafe pedestrian mobility, this large width itself provided a good opportunity for diversifying the mobility options and thus help improve walkability and bikeability conditions. The Abu Dhabi Urban Street Design Manual (Idaho Smart Growth \& Urban Land Institute 2010), the street design standard document provided by

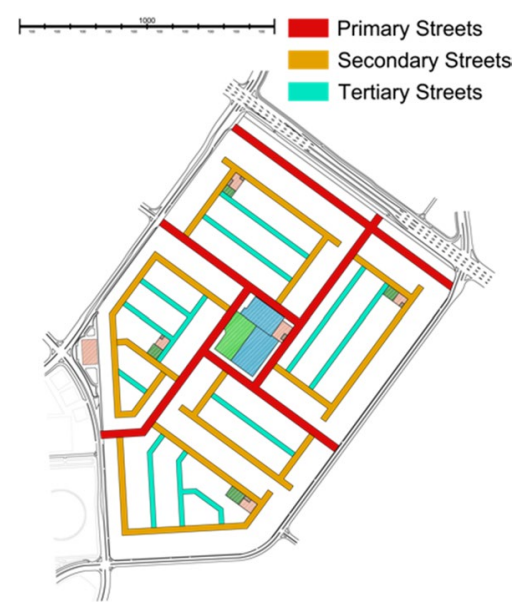

Fig. 23 Existing street types in Al Barsha North 2 
the local government's planning authority in Abu Dhabi, was used to suggest a new set of street layouts. Accordingly, the street widths were divided into five general segments including: (1) Through or Pedestrian Walkway, (2) Furnishing, (3) Cycling Lane or Bike Path, (4) On-Street Parking and (5) Driveway, with landscape buffers separating them for the sake of safety and pleasantness of the environment (Abu Dhabi Urban Planning Council 2010). These five segments were complied with the referenced standards in terms of dimensions, required elements, and required safety measures as illustrated in Figs. 24 and 25.

As noticed in Al Barsha 2 neighborhood, there is a walkway between the plots' residential blocks usually at each five housing plots with a width of about 6 meters. Unfortunately, these walkways have been mostly left abandoned with a sandy ground cover making them highly prone to illegal activities that undermine safety and security (Fig. 26).

In the redevelopment scenario these 'urban gaps' were utilized for facilitating the pedestrian movements, as originally planned (Fig. 27). Such redeveloped walkways

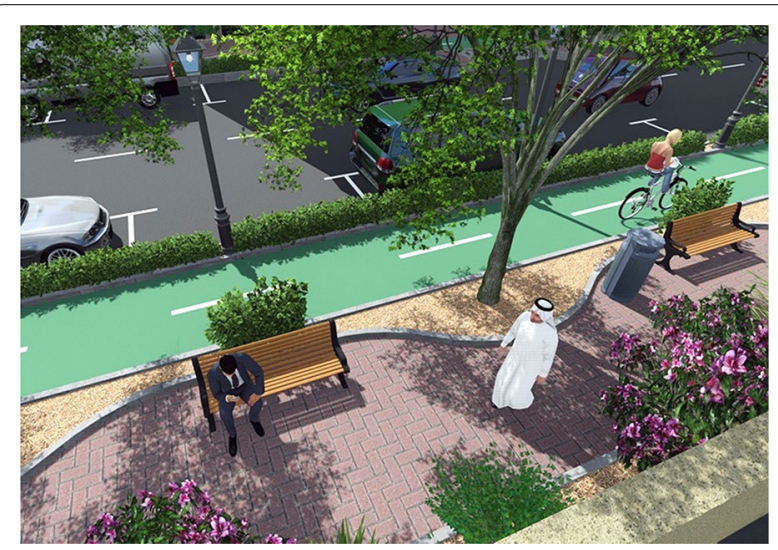

Fig. 24 An example of the applicable street layout-secondary streets in the redevelopment scenario

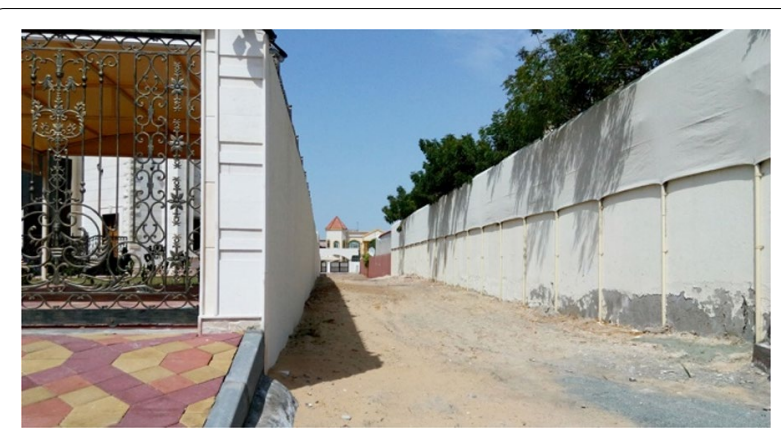

Fig. 26 The abandoned 6 meters' walkways between housing blocks in Al Barsha North 2

have provided a unique opportunity for the improvement of pedestrian and cycling networks in a way that would contribute to a highly mobilized urban form when associated with the redeveloped mobility networks. The redeveloped in-between walkways/cycling lanes have significantly improved the spatial integration of the neighborhood's mobility networks (Fig. 28 and 29), and considerably enhanced the walkability and bikeability in the neighborhood (Fig. 30).

Security in the public realm has noticeably enhanced as well after integrating these redeveloped walkways/cycling lanes with the other existing/redeveloped pedestrian and cycling networks. According to the referenced benchmarking above (Figs. 4 and 5), the redeveloped mobility networks and the decentralized pattern of amenities provision resulted from the redefined land-use plan, would make the neighborhood 'very walkable' and turn it also into a 'bikers' paradise' (Fig. 30). On the other hand, some measures were proposed for restraining the private car movement and encouraging the non-motorized modes of mobility. One of these measures is blocking the end of every tertiary street by telescoping or pop-up street bollards that allow motorized access only in case of emergency (Fig. 31). This simple action would restrain the

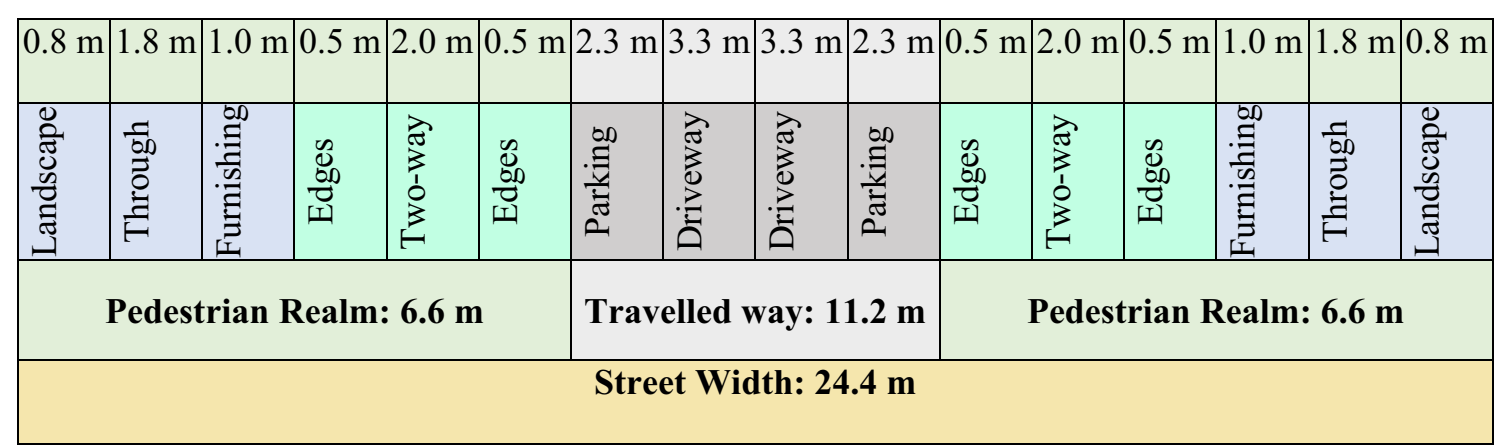

Fig. 25 As example of the redeveloped five segments of the secondary streets 


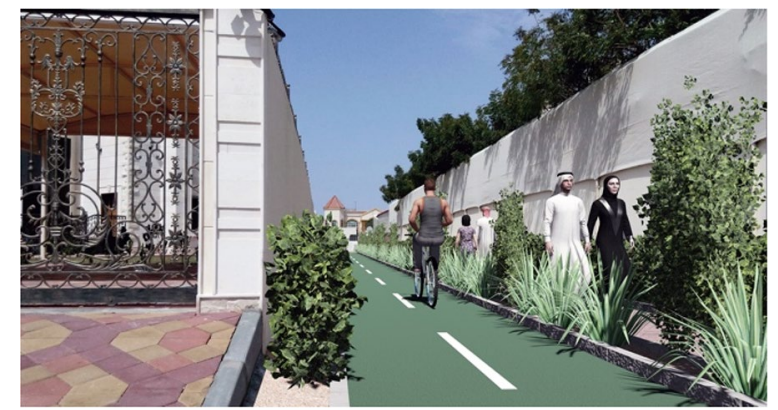

Fig. 27 The 6 meters' walkways between housing blocks after redevelopment

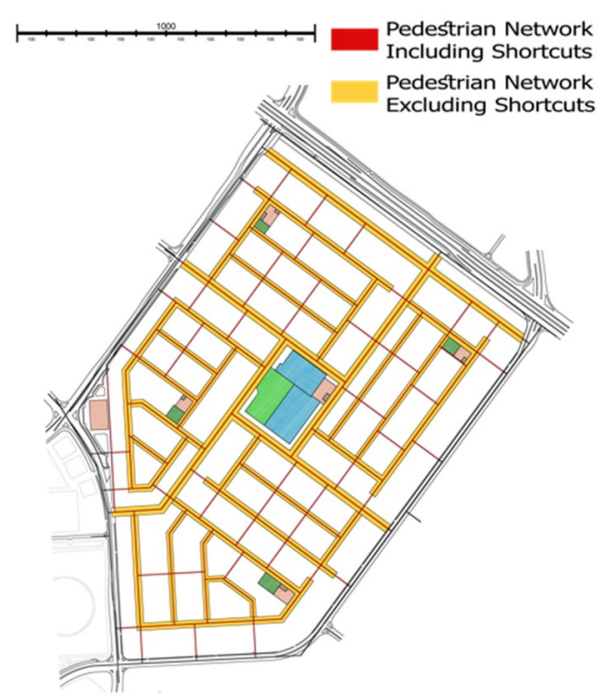

Fig. 28 The redeveloped mobility network in the proposed redevelopment scenario

private car movements as explicated in the Integration simulation of the DepthmapX tool of the vehicular network in the two cases of 'before' and 'after' the redevelopment (Figs. 32 and 33) within affecting the integration of the walking or cycling mobility networks. Accordingly, walking and cycling will take precedence over private cars, which is a major contributor for realizing social sustainability objectives in terms of mobility.

As another important contributing factor to the mobility of the neighborhood, the currently provided public transport was studied above (using DepthmapX), and accordingly in this redevelopment scenario an alternative plan was proposed. In this plan one or both of the exiting bus routes F30 and 37's paths was altered and an additional bus stop was added, while keeping the same movement direction (Fig. 34). This significantly enhanced the accessibility of a greater number of houses to the public transport nodes (bus stops) in the neighborhood.

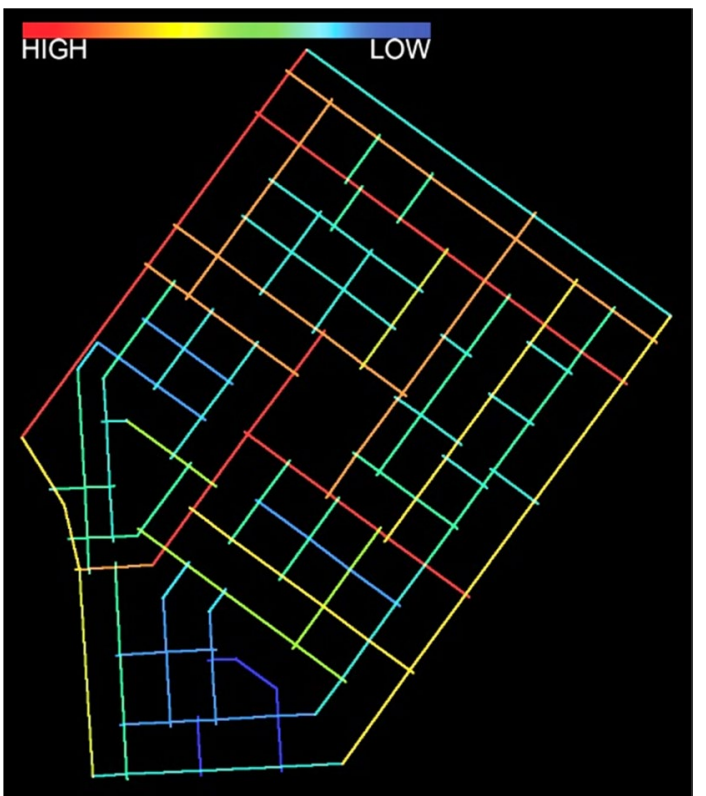

Fig. 29 More spatial integration of mobility networks after the inclusion of redeveloped walkways/cycling lanes, as simulated by the DepthmapX tool

It is important also to note that by increasing the population density, providing a greater number of bus-routes and stops throughout the day would also be economically feasible. So, all in all, by applying these redevelopment strategies and actions, Al Barsha North 2 would be able to enhance its mobility in a socially sustainable manner.

Accessibility, as a vital principle of social sustainability of the urban form, would also be significantly improved by the implementation of the redeveloped street networks, in which the walking/cycling distances are decreased, the vehicular movements are restrained, and walking and cycling are prioritized. Accessibility is also supported by the increased population density, the enhanced quality of supplied amenities, and the highquality environment. Achieving accessibility requires considering "equity" or inclusive design measures in the redeveloped urban form. Accordingly, a convenient 1:12 sloped ramp access was proposed at every building entrance, and also at the two ends of every groundlevel crosswalk. This would help the urban form of the neighborhood meet the accessibility principle of social sustainability.

Lastly, besides the design and aesthetic reasons underlying the necessity of high-quality landscaping in the redeveloped streets' layouts, the role of locally adaptive plants and shadow-casting trees proposed in the redevelopment scenario is crucial in mitigating the effect of the harsh weather conditions in Dubai. This would encourage 


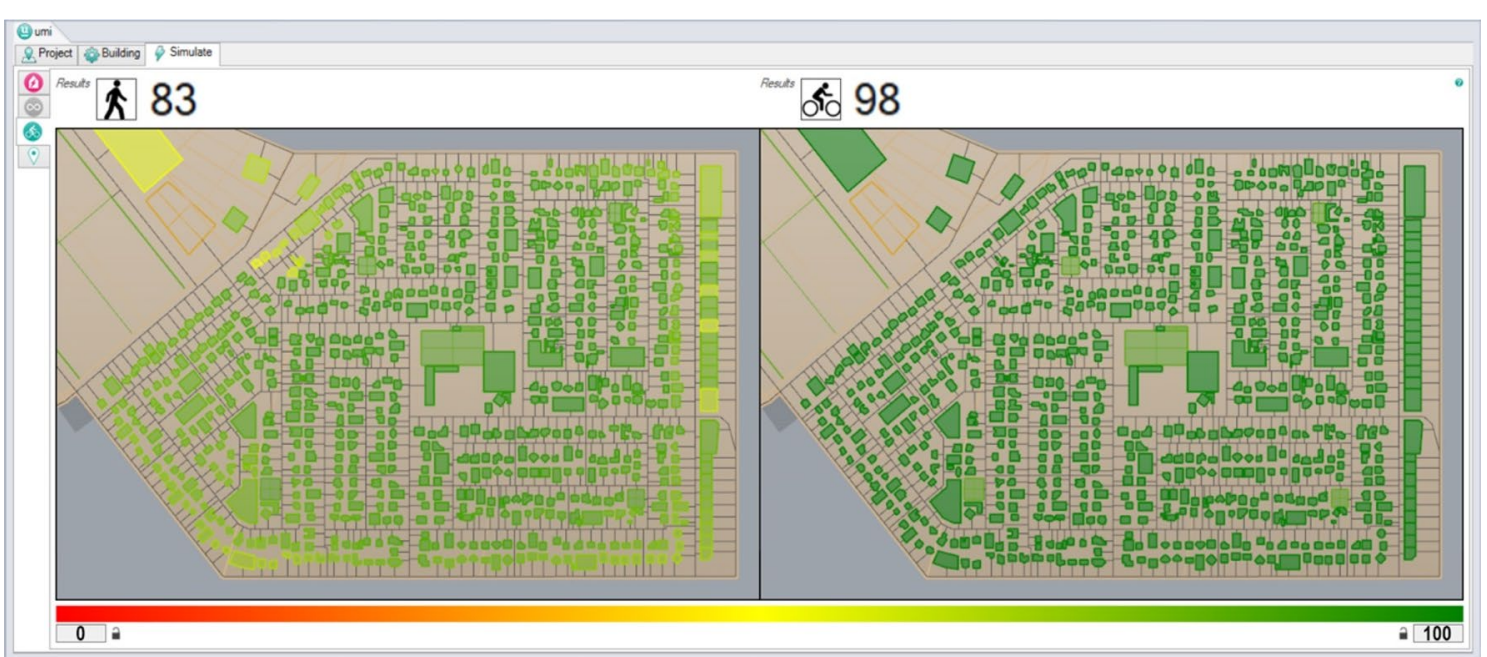

Fig. 30 Walkability and bikeability scoring analysis of the redevelopment scenario as performed using the UMI tool

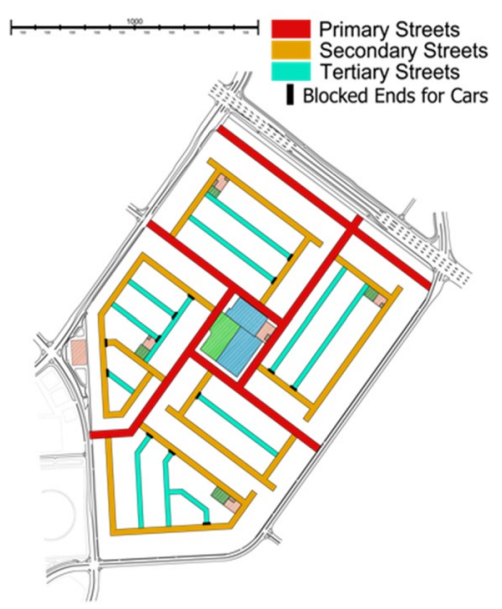

Fig. 31 Restrained vehicular movements in the redeveloped scenario

people to walk and cycle to their destinations, including the bus stops, within the neighborhood. For street furnishings, providing setting benches at convenient distances along the sidewalks was proposed in the redevelopment scenario as an essential tool to allow people to rest while walking, when needed, and to also create nodes for social engagement and interactions. Accordingly, the overall environmental quality of the neighborhood will be improved, and thus, will be leading to a more socially sustainable neighborhood.

From the above discussions, it is realized that $\mathrm{Al} \mathrm{Bar-}$ sha North 2 neighborhood has a good potential of being redeveloped into a more socially sustainable neighborhood, mainly through implementing the defined

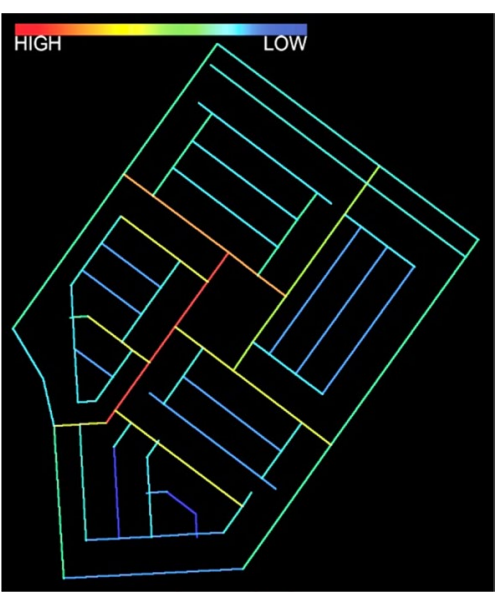

Fig. 32 Before redevelopment; Integration of the current vehicular network

redevelopment guidelines and actions to its existing urban form. Table 3 illustrates an admittedly somehow "subjective", but convincing, comparative evaluation of the extent to which the studied and discussed measures have contributed to the neighborhood's redevelopment into a more socially sustainable version, if compared with its status quo. To ease the assessment of each indicator and the overall attainment level, the following 'intuitive' scale from 0 to 10 was assigned where, for each indicator: Not Achieved $=0$, Poorly Achieved $=2.5$, Partially Achieved $=5.0$, Mostly Achieved $=7.5$, Fully Achieved $=10$.

As noticed in this Table, in the redevelopment scenario most of the social sustainability indicators could be met 


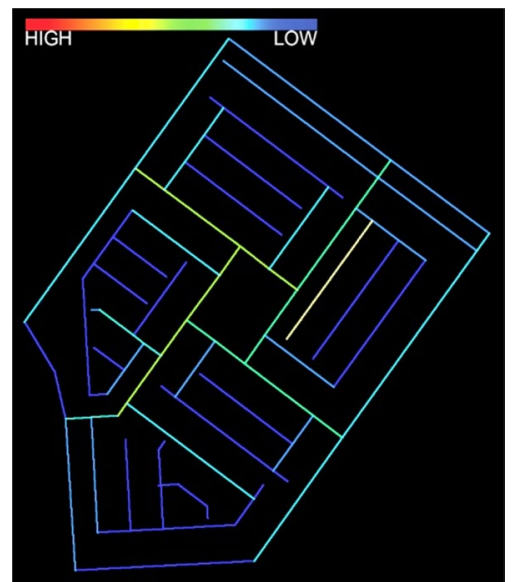

Fig. 33 After redevelopment; Disintegration of vehicular network to restrain private car movement

by the implementation of the redevelopment guidelines and associated actions. Still, some others have been met to a somewhat limited extent including public transport.

The proposed IMTM tool was first used to assess an existing urban neighborhood in Dubai in terms of its compliance with social sustainability principles. The results obtained from this assessment indicated the significant effect of urban form on its social sustainability performance. Density was found to be an influential prerequisite for achieving social sustainability of the neighborhood and a key redevelopment strategy for it. The low quality and limited variety of amenities and services offered in the studied neighborhood have not satisfied the local needs of the residents and thus were not mostly considered as viable mobility destinations. This aspect seems also interlinked with 'density' because, by definition, density is a key contributor to the viability, quality, and diversity of amenities and services in a neighborhood (Barton 2000; Dempsey et al. 2010). In addition to the shortage of high-quality and diverse locally provided amenities in the neighborhood, the low degree of walkability and bikeability was a third major social sustainability related problem. This cannot be attributed only to the long walking distances, but also to the lack of a proper land-use plan and the absence of a fitting design for the non-motorized mobility networks. This has increased private car dependency among the residents and consequently undermined the level of liveliness within the neighborhood. On another front, the lack of vibrancy in the public realm of the neighborhood is considered a degrading factor to its security; as the neighborhood environment lacks community surveillance (Newman 1996), and it thus requires active and costly police patrol monitoring.

The output of the IMTM guided assessment was used afterwards to develop relevant redevelopment guidelines and strategies for enhancing social sustainability in the exiting urban form bearing in mind that the neighborhood is already built and inhabited, which causes multiple constraints for the proposed changes. The redevelopment strategies/guidelines were related to enhancing the exiting urban form in terms of its social sustainability related major influential issues including

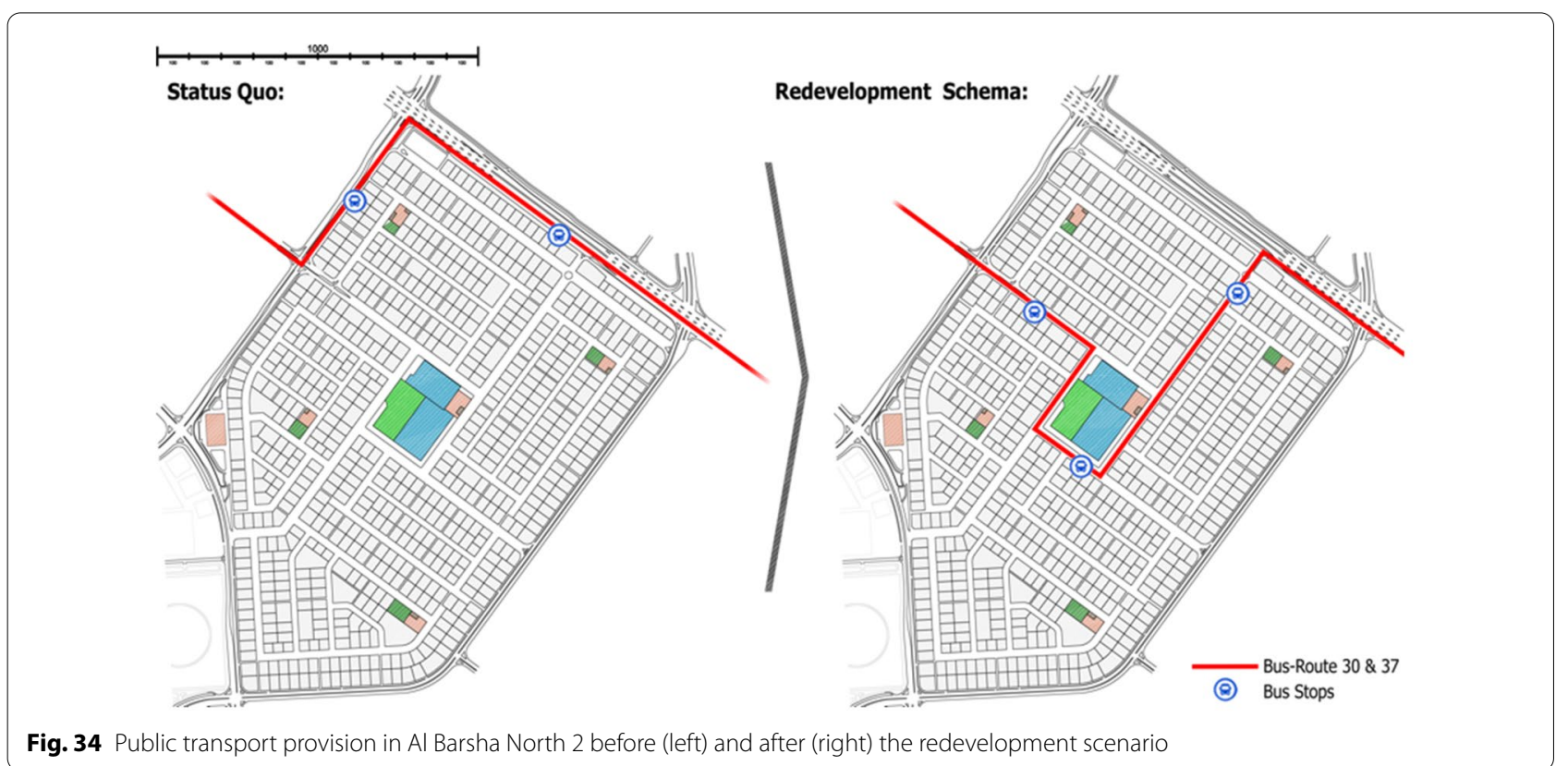


Table 3 Comparative assessment of social sustainability indicators in the redeveloped scenario of Al Barsha North 2 neighborhood vs. its status quo

\begin{tabular}{|c|c|c|c|c|}
\hline & Principles & Indicators & Status Quo & $\begin{array}{l}\text { Redeveloped } \\
\text { Scheme }\end{array}$ \\
\hline 1 & Density & Population Density (40 to 50 pph) and Urban compactness (Floor Area Ratio) & 2.5 & 10.0 \\
\hline \multirow[t]{3}{*}{2} & \multirow[t]{3}{*}{ Accessibility } & \multirow{2}{*}{$\begin{array}{l}\text { (Services and facilities located within walk- } \\
\text { able and bikeable `s through well-defined } \\
\text { pathways/cycling lanes) }\end{array}$} & 2.5 & 10 \\
\hline & & & 2.5 & 10 \\
\hline & & Services accessible for everyone (Equity) & 5.0 & 10.0 \\
\hline \multirow[t]{6}{*}{3} & \multirow[t]{6}{*}{ Mobility } & $\begin{array}{l}\text { (A safe, connected and well-designed } \\
\text { pedestrian and cycling infrastructure) }\end{array}$ & 2.5 & 10.0 \\
\hline & & pedestrian and cycling infrastructure) & 0 & 10.0 \\
\hline & & Availability of accessible and cost-effective "Public Transport" & 2.5 & 5.0 \\
\hline & & Restrained car traffic (prioritization of non-privatized modes of movement) & 0 & 10.0 \\
\hline & & Decentralized provision of services & 5.0 & 10.0 \\
\hline & & Transit Oriented Development & 2.5 & 7.5 \\
\hline \multirow[t]{3}{*}{4} & \multirow[t]{3}{*}{ Integration } & Spatial connectivity with adjacent neighborhoods. & 5.0 & 10 \\
\hline & & Spatial connectivity of the neighborhood's street network & 2.5 & 2.5 \\
\hline & & $\begin{array}{l}\text { Mutual supporting role among the neighborhood and its surrounding neighborhoods in } \\
\text { terms of provided amenities and services) }\end{array}$ & 2.5 & 2.5 \\
\hline 5 & Choice \& diversity & $\begin{array}{l}\text { Diverse range of high-quality services, housing types, non-car-based jobs, open spaces, } \\
\text { and modes of mobility }\end{array}$ & 2.5 & 10.0 \\
\hline \multirow[t]{3}{*}{6} & \multirow[t]{3}{*}{ Mixed-use } & Mixed land-use of the neighborhood plan & 2.5 & 10.0 \\
\hline & & $\begin{array}{l}\text { Availability of quality open spaces that can accommodate various social and commercial } \\
\text { activities }\end{array}$ & 7.5 & 10.0 \\
\hline & & Ability to undertake multi-purpose trips & 2.5 & 10.0 \\
\hline 7 & Environmental quality & Physical, psychological, thermal, and visual comfort & 5.0 & 10.0 \\
\hline \multirow[t]{6}{*}{8} & \multirow[t]{6}{*}{ Safety } & Avoiding urban sprawl & 2.5 & 7.5 \\
\hline & & Calmed road traffic & 2.5 & 10.0 \\
\hline & & Streets safe for everyone, not just cars & 2.5 & 10.0 \\
\hline & & Dedicated pathways for pedestrians & 2.5 & 10.0 \\
\hline & & Safe and integrated network for cyclists & 0 & 10.0 \\
\hline & & Safe access to high-quality public transport nodes & 2.5 & 5.0 \\
\hline \multirow[t]{4}{*}{9} & \multirow[t]{4}{*}{ Security } & Cul-de-sacs avoided & 5.0 & 10.0 \\
\hline & & Community surveillance & 2.5 & 7.5 \\
\hline & & Dwelling units occupied mostly by owners & 7.5 & 7.5 \\
\hline & & Rent/property price (social stratum) & 7.5 & 7.5 \\
\hline \multirow[t]{4}{*}{10} & \multirow[t]{4}{*}{ Social capital } & $\begin{array}{l}\text { Available social gathering nodes (regular occurrence of social interactions leading to social } \\
\text { networks) }\end{array}$ & 2.5 & 7.5 \\
\hline & & Encouraged people encountering (through walking) & 2.5 & 10.0 \\
\hline & & $\begin{array}{l}\text { Distinctive urban design and high-quality services and facilities (increase sense of belong- } \\
\text { ing) }\end{array}$ & 2.5 & 10.0 \\
\hline & & Community participation (increases trust) & 0 & 7.5 \\
\hline \multicolumn{2}{|c|}{ Total average } & & 3.05 & 8.67 \\
\hline
\end{tabular}

density, land-use, mobility networks, streets layouts, and the built environment's design aspects. As a result, the key strategies for achieving a more socially sustainable neighborhood for the studied case study encompasses increased density by infill techniques, mixed land-use, diversified housing types and decentralized amenities, diversified mobility options, improved spatial integration of the mobility networks while restraining the private cars movement, improved accessibility, adapted urban landscape, and finally enhanced quality of amenities and services. The implementation of these several redevelopment strategies/guidelines was successful in developing a scenario for an enhanced version of the exiting urban form of the studied neighborhood. This has been proved through comparing the existing neighborhood with its redeveloped plan using the IMTM and based on the 
defined framework for social sustainability principles and indicators. Accordingly, the IMTM has proved its reliability in validating the redevelopment measures.

\section{Conclusions}

Computational simulation techniques are commonly adopted in studying environmental sustainability redevelopment. However, the current trend of studies on social sustainability of residential neighborhoods is often based on analytical reasoning approaches that in many cases adopt statistic questionnaire methods and/or qualitative analyses of unstructured/semi-structured interviewing and field observations methodologies. For defining effective urban redevelopment strategies and actions to enhance social sustainability, both the reliability of the assessment and the comparability of the alternative solutions are playing key roles. In addition, because the issues affecting social sustainability in urban neighborhoods are interrelated in one way or another, they should be handled with an integrated multi-tool method. Accordingly, in this research, the proposed Integrated Measuring Tools Method (IMTM) has satisfied this need and it proved being efficient in studying social sustainability issues in both an existing urban development context and its redevelopment scenario, to ultimately attain a more socially sustainable urban neighborhood. Utilizing the IMTM, that involves a combination of relevant computational simulation techniques and qualitative assessment tools, has helped defining more reliable strategies and recommended actions for socially sustainable redevelopment of urban neighborhoods in Dubai.

Eventually, given the lack of well-defined standards for socially sustainable redevelopment of neighborhoods not only in Dubai, but also in the similar residential developments in the region, the proposed Integrated Measuring Tools Method (IMTM) can contribute to the attainment of socially sustainable neighborhoods through utilizing it as a social sustainability assessment/redevelopment and validation tool.

\section{Limitations and further research}

As social sustainability is a highly contextual topic, accessing the residents of a neighborhood in a particular geographical and cultural context and investigating the contributing factors to their satisfaction with the living environment would help the research find a more diverse set of opportunities and solutions for improving social sustainability aspects of the exiting urban form. Moreover, studying a greater number of neighborhoods would allow for a higher degree of generalizability for the research outcomes. These limitations are recommended as investigation topics for further research.

\section{Acknowledgements}

This research is funded by the Emirates Center for Happiness and Wellbeing Research at the United Arab Emirates University, Grant Code G00003226.

\section{Authors contributions}

SMH: significantly developed the Proposed Integrated Measuring Tools Method (IMTM) for Assessing Social Sustainability Indicators in Exiting Neighbourhoods. Shared the Discussion and Conclusions with the second corresponding author. KGA: significantly contributed in developing the Conceptual Framework for Social Sustainability Principles and Indicators. Shared the Discussion and Conclusions with the first author. All authors read and approved the final manuscript.

\section{Author details}

${ }_{1}^{1}$ Architectural Engineering Department, College of Engineering, United Arab Emirates University, P. O. Box: 13393, Al Ain, UAE. ${ }^{2}$ Emirates Center for Happiness \& Wellbeing, United Arab Emirates University, P. O. Box: 13393, Al Ain 15551, UAE.

Received: 11 August 2020 Accepted: 28 November 2020

Published online: 06 January 2021

\section{References}

Abu Dhabi Urban Planning Council (2010) Abu Dhabi Urban Street Design Manual, Abu Dhabi Vision 2030. Department Of Urban Planning And Municipalities, Abu Dhabi

Abu Dhabi Urban Planning Council (2012) Part II, The Community Facilities Standards. Abu Dhabi Community Facility Planning Standards, Abu Dhabi Vision 2030. Department Of Urban Planning And Municipalities, Abu Dhabi, pp 23-64

Adriaanse C (2011) On measuring and explaining neighborhood success. IOS Press, under the imprint Delft University Press, Amsterdam

Alawadi K (2017) Rethinking Dubai's urbanism: generating sustainable form-based urban design strategies for an integrated neighborhood. Cities 60:253-366

Avila M, Ines M (2001) Factors that Influence the Social Life and Vitality of Public Open Spaces in Maracaibo-Venezuela. Case Study: Plaza de la Madre and Plaza de la República. Virginia Tech, Blacksburg

Azmi DI, Karim HA (2012) Implications of walkability towards promoting sustainable urban neighbourhood. Proc Soc Behav Sci. 50:204-213

Barton H (2000) Sustainable communities: the potential for eco-neighborhoods. Earthscan, London

Berg P, Sharmeen F, Weijs-Perrée M (2017) On the subjective quality of social interactions: influence of neighborhood walkability, social cohesion and mobility choices. Transp Res Part A. 106:309-319

Bramley G, Brown C, Dempsey N, Power S, Watkins D (2010) Social acceptability. In: Jenks M, Jones C (eds) Dimensions of sustainable city. Future City, vol 2. Springer, Dordrecht, pp 105-128

Campoli J (2012) Made for walking: density and neighborhood form. Lincoln Institute of Land Policy, Amesbury

Carmona M, Heath T, Oc T, Tiesdell S (2003) Public places, urban spaces: the dimensions of urban design. Architectural Press, Oxford

de Geus M (1999) Ecological Utopias: Envisioning the Sustainable Society. International Books, Utrecht

Dempsey N, Brown C, Raman S, Porta S, Jenks M, Jones C, Bramley G (2010) Elements of urban form. In: Jenks M, Jones C (eds) Dimensions of the sustainable city. Future City, vol 2. Springer, Dordrecht, pp 21-51

Dempsey N, Brown C, Bramley G (2012) The key to sustainable urban development in UK cities? The influence of density on social sustainability. Progr Plan 77:89-141

Dillard J, Dujon V, King MC (eds) (2009) Understanding the social dimension of sustainability. Routledge, New York

Dubai Land Department, "Rental Index," Government of Dubai. https://www. sim.gov.ae/Public/RentallndexPage.aspx?!ng=en. Accessed Sep 2019

Eizenberg E, Jabareen Y (2017) Social sustainability: a new conceptual framework. Sustainability 9(1):68

Ferguson N, Woods L (2010) Travel and mobility. In: Jenks M, Jones C (eds) Dimensions of the sustainable City, Future city, vol 2. Springer, Dordrecht, pp 53-74 Furlan R, Petruccioli A, Major MD, Zaina S, Zaina S, Alsaeed M, Saleh D (2019) The urban regeneration of west-bay, business district of Doha (State of 
Qatar): a transit-oriented development enhancing livability. Urban Manag $8(1): 126-144$

Ghahramanpouri A, Lamit H, Sedaghatni S (2013) Urban social sustainability trends in research literature. Asian Soc Sci 9(4):185-193

GIS, "2gis.com," [Online]. Available: https://2gis.ae/dubai

Google, Google Earth Engine. https://earthengine.google.com/timelapse/

Harris J, Goodwin NR (2001) Volume introduction. In: Harris J, Wise T, Gallagher K, Goodwin NR (eds) Survey of sustainable development: social and economic dimensions. Island Press, Washington

Hassan AM, Lee H (2015) Toward the sustainable development of urban areas: an overview of global trends in trials and policies. Land Use Policy 48:199-212

Hassen N, Kaufman P (2016) Examining the role of urban street design in enhancing community engagement: a literature review. Health Place 41:119-132

Holland C, Clark A, Katz J, Peace S (2007) Social interactions in urban public places. Policy Press, Bristol

Idaho Smart Growth \& Urban Land Institute, Idaho District Council, "Quality Infill Recommendations and Tools," Idaho Smart Growth, Boise, 2010

Jabareen YR (2006) Sustainable urban forms: their typologies, models, and concepts. Plan Educ Res 26:38-52

Jalaladdini S, Oktay D (2012) Urban public spaces and vitality: a sociospatial analysis in the streets of two Cypriot towns. Proc Soci Behav Sci. 35:664-674

Jenks M, Jones C (2010) Issues and concepts. In: Jenks M, Jones C (eds) Dimensions of the sustainable city. Future City, vol 2. Springer, Dordrecht, pp $1-19$

Karji A, Woldesenbet A, Khanzadi M, Tafazzoli M (2019) Assessment of social sustainability indicators in mass housing construction: a case study of Mehr housing project. Sustain Cities Soc 50:101697

Kolczak A, "National Geographic," National Geographic Partners LLC, 8 December 2017. https://www.nationalgeographic.com/environment/urban -expeditions/green-buildings/design-trends-sustainability-cities-welln ess-climate-change/. Accessed Oct 2019]

Leyden KM (2003) Social capital and the built environment: the importance of walkable neighborhoods. Am J Public Health 93(9):1546

Loo BP, Cheng AH, Nichols SL (2017) Transit-oriented development on greenfield versus infill sites: some lessons from Hong Kong. Landsc Urban Plan 167:37-48

Lynch K (1981) A theory of good city form. MIT Press, Cambridge, pp 111-120

Makarewicz C, Németh J (2018) Are multimodal travellers more satisfied with their lives? A study of accessibility and wellbeing in the Denver, Colorado metropolitan area. Cities 74:179-187

Marans RW, Couper M, Measuring the quality of community life: a program for longitudinal and comparative international research. Proceedings of the Second International Conference on Quality of Life in Cities, Singapore, 2000

Miller JS, Hoel LA (2002) The "smart growth" debate: best practices for urban transportation planning. Soc Econ Plan Sci 36(1):1-24

Mouratidis K (2018) Built environment and social well-being: how does urban form affect social life and personal relationships? Cities 74:7-20

Mouratidis K (2019) Compact city, urban sprawl, and subjective well-being. Cities 92:261-272

Nabil NA, AbdEldayem GE (2015) Influence of mixed land-use on realizing the social capital. HBRC J 11(2):285-298

Newman O (1996) Creating defensible space. Office of PD\&R at U.S. Department of Housing and Urban Development, Washington
Norhafizah AR, Shamsuddin S, Ghani I (2015) What makes people use the street? Towards a liveable urban environment in Kuala Lumpur City Centre. Proc Soc Behav Sci. 170:624-632

Putnam RD (2000) Bowling alone: The collapse and revival of American community. Simon \& Schuster, New York

Rakha T, Reinhart CF, A carbon impact simulation-based framework for land use planning and non-motorized travel behavior interactions, in 13th Conference of International Building Performance Simulation Association, Chambéry, 2013

Road and Transport Authority, "RTA," Government of Dubai. Available: http:// wojhati.rta.ae. Accessed Sep 2019

Smith MK, Neighbourhoods and regeneration. Theory, practice, issues, the encyclopadia of informal education, London, 2011

Space Syntax Laboratory, "spacesyntax.net," Bartlett School of Architecture, University College London, 2001. http://otp.spacesyntax.net/softwareand-manuals/depthmap/. Accessed Oct 2019

Sung H, Lee S (2015) Residential built environment and walking activity: empirical evidence of Jane Jacobs' urban vitality. Transp Res Part D 41:318-329

Sustainable Design Lab, "Urban Modelling Interface (umi)," Massachusetts Institute of Technology, 2013.http://web.mit.edu/sustainabledesignlab/ projects/umi/index.html. Accessed Oct 2019

Udell T, Daley M, Johnson B, Tolley R (2014) Does density matter? The role of density in creating walkable neighbourhoods. National Heart Foundation of Australia, Melbourne

Un-Habitat Enhancing Urban (2007) Safety and security. Earthscan, London

Van Dyck D, Cardon G, Deforche B, De Bourdeaudhuij I (2011) Do adults like living in high-walkable neighborhoods? Associations of walkability parameters with neighborhood satisfaction and possible mediators. Health Place 17(4):971-977

Walk Score, "walkscore.com," https://www.walkscore.com/methodology.shtml Wang Y, Li L, Zhu X, Wu B, Li L (2015) Evaluation of urban redevelopment impact on non-motorized traffic. J Traffic Transp Eng 2(3):187-197

Wang Y, Mishra S, Ye X, Li L, Wu B (2017) The application of integrated multimodal metropolitan transportation model in Urban Redevelopment for Developing Countries. Transp Res Proc 25:2990-3002

Wassenberg F, Dijken K, A practitioner's view on neighbourhood regeneration: Issues, approaches and experiences in European cities," Nicis Institute, The Hague, 2011

Welle B, Liu Q, Li W, Adriazolasteil C, King R, Sarmiento C, Obelheiro M (2015) Cities safer by design: guidance and examples to promote traffic safety through urban and street design. World Resource Institute, Washington

Williams K, Dair C, Lindsay M (2010) Neighbourhood design and sustainable lifestyles. In: Jenks M, Jones C (eds) Dimensions of sustainable city. Future City, vol 2. Springer, Dordrecht, pp 183-214

Wood L, Shannon T, Bulsara M, Pikora T, McCormack G, Giles-Corti B (2008) The anatomy of the safe and social suburb: an exploratory study of the built environment, social capital and residents' perceptions of safety. Health Place 14(1):15-31

Zaina S, Zaina S, Furlan R (2016) Urban planning in Qatar: strategies and vision for the development of transit. Aust Plan 53(4):286-301

\section{Publisher's Note}

Springer Nature remains neutral with regard to jurisdictional claims in published maps and institutional affiliations. 